Int. J. Dev. Biol. 52: 837-856 (2008)

doi: $10.1387 /$ ijdb.0723961s

\title{
Sex-determining mechanisms in insects
}

\author{
LUCAS SÁNCHEZ \\ Centro de Investigaciones Biológicas (C.S.I.C), Madrid, Spain
}

\begin{abstract}
Sex determination refers to the developmental programme that commits the embryo to either the male or the female pathway. The animal kingdom possesses a wealth of mechanisms via which gender is decided, all of which are represented among the insects. This manuscript focuses on a number of insects for which genetic and molecular data regarding sex determination mechanisms are available. The sex determination genetic cascade of Drosophila melanogaster is first discussed, followed by an analysis of the sex determination genes of other dipteran and nondipteran insects. Representative examples of sex determination mechanisms that differ in their primary signal are also described. Finally, some evolutionary aspects of these mechanisms are discussed.
\end{abstract}

KEY WORDS: Drosophila, Apis, Sciarids, Coccids, heterochromatisation, chromosome elimination

\section{Introduction}

Perpetuation by sexual reproduction is the rule within the animal kingdom. Males and females are different at the morphological, physiological, and behavioural levels. This sexual dimorphism results from the integration of two processes: sex determination and sexual differentiation. Sex determination refers to the developmental programme that commits the embryo to either the male or the female pathway. The genes underlying this programme are the sex determination genes. Sexual differentiation refers to the expression of the sex-cytodifferentiation genes (which are controlled by the sex determination genes), the expression of which give rise to the formation of the sexually dimorphic structures that characterise the male and female adults.

The animal kingdom possesses a wealth of mechanisms via which gender is decided (Bull, 1983). This is no more evident than among insects, among which all known types of sex determination mechanism are represented. These mechanisms can be classified into three main categories depending on the origin of the primary, genetic, sex determination signal, which can be zygotic, maternal or environmental.

Sex determination can be based on chromosome differences, one sex being homomorphic and the other heteromorphic for the sex chromosomes. This is seen in Drosophila, in which sex determination is based on the ratio between the $X$ and the autosomal chromosomes: females are $2 \mathrm{X} ; 2 \mathrm{~A}$ and males are $\mathrm{X} ; 2 \mathrm{~A}$ ( $X$ stands for the $X$ chromosome and $A$ stands for a haploid complement of autosomes). Recently, it has been reported that the X/A signal predicts sexual fate instead of actively specifies it, so that it is the number of $X$ chromosomes rather than the $X / A$ signal what has an instructive role in sex determination (Erickson and Quintero, 2007, and cites therein). In other species, the heteromorphic sex carries the male-determining factors on the $Y$ chromosome. This is true of the tephritid flies (Ceratitis, Bactrocera and Anastrepha) and Musca. In some Musca populations, the male-determining factor may, instead, be located on one of the autosomes. In all these examples, the female is the homomorphic sex $(X X)$, and the male is the heteromorphic sex (XY). However, there are insects, such as the lepidopterons (butterflies and moths), in which the male is the homomorphic sex $(Z Z)$ and the female the heteromorphic sex $(Z W)$ (the letters $Z$ and $W$ are used to distinguish this system from the $X Y$ system) (for a revision on the relationships between $Z W$ and $X Y$ sex chromosome systems see Ezaz et al., 2006, and cites therein). In other genera, the chromosomal difference between males and females is based on haploidy/diploidy, e.g., in Apis, females are diploid and males are haploid.

In most species, the sex of an individual is fixed at fertilisation, as in Drosophila, Ceratitis, Bactrocera, Anastrepha and Musca, the chromosomal constitution of the zygote being a direct consequence of the chromosomal constitution of the gametes (Bull, 1983). However, in other species the chromosomal differences determining sex are brought about by the specialised behaviour of sex chromosomes during the first stages of embryonic development. The differential elimination of sex chromosomes as a

Abbreviations used in this paper: CSD, complementary sex determination.

\footnotetext{
*Address correspondence to: Lucas Sánchez. Centro de Investigaciones Biológicas, Ramiro de Maeztu 9, E-28040 Madrid, Spain. Tel: +34-91-837-3112. Fax: +34-91-536-0432. e-mail: Isanchez@cib.csic.es - Web http://www.cib.csic.es/en/grupo.php?idgrupo=17
} 
mechanism of sex determination is seen in Sciara, in which all zygotes start with the $3 \mathrm{X} ; 2 \mathrm{~A}$ constitution; the loss of either one or two paternal $X$ chromosomes determines whether the zygote

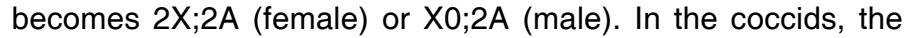
differential elimination or heterochromatisation of all the paternal chromosomes gives rise to functional diploid or haploid zygotes, which develop into females or males respectively.

Finally, environmental sex determination is also seen among the insects. The sex ratio of some Sciara species depends on the temperature at which the embryos develop (see below).

At the gene level, sex can be controlled by a single locus or by multiple loci, the gene or genes involved showing zygotic and/or maternal effects (Bull, 1983). A classic example of sex determination based on a single locus with several alleles - complementary sex determination (CSD) - is seen in the honeybee Apis mellifera. Heterozygotes at the sex-determining locus are normal fertile females, whereas homozygous diploid zygotes develop into sterile males. Haploids are hemizygous at the sex locus and develop into functional males (see below).

The blowfly Chrysomya rufifacies provides an example of maternal sex determination in which no heteromorphism of the sex chromosomes exists, the sex of the zygote being exclusively determined by the genotype of the mother. In this insect, two types of female exist: gynogenic females, which only produce female offspring, and androgenic females, which only produce male offspring. The gynogenic females are heterozygous for the gene

Femaleness

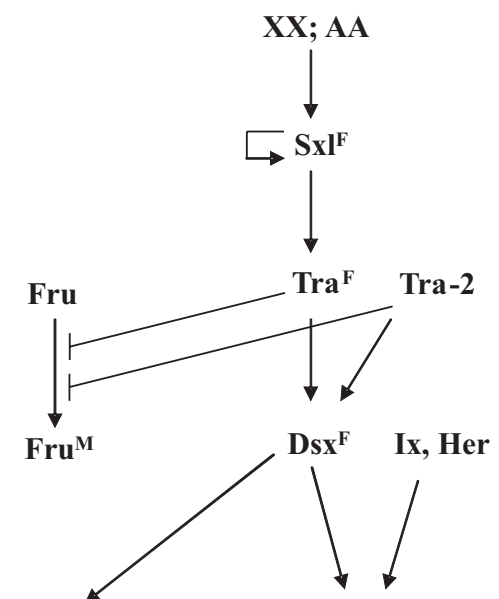

Female CNS

Female sexual

behaviour

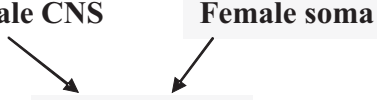

\section{Maleness}

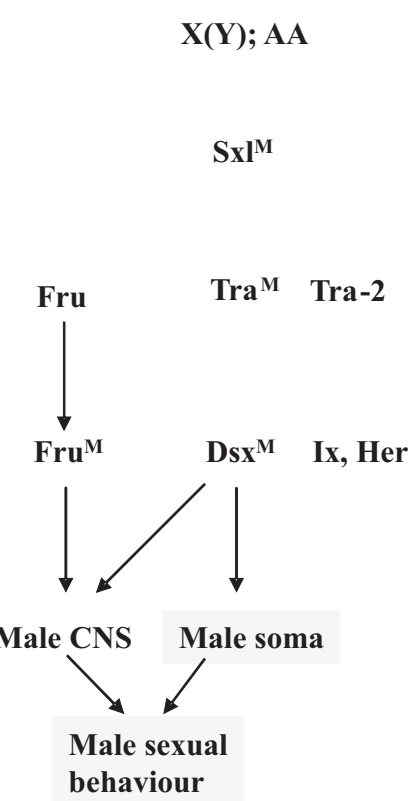

Fig. 1. The sex determination gene cascade in Drosophila melanogaster. $S x I^{F}$ and $S x M^{M}$ stand for functional female and non-functional truncated male SxI protein respectively. Tra ${ }^{F}$ and $\mathrm{Tra}^{\mathrm{M}}$ stand for functional female and non-functional truncated male Tra protein respectively. DsX $x^{F}$ and DsX ${ }^{M}$ stand for functional Dsx protein in females and males respectively. $\mathrm{Fru}^{\mathrm{M}}$ stands for functional Fru protein in males. In the absence of the X/A signal in males, the default state corresponds to the production of $S X^{M}, \operatorname{Tra}^{M}, D s X^{M}$ and $F r u^{M}$ proteins. Ix and Her proteins are produced in both sexes. CNS, central nervous system. For description of the genes and their regulation, see text.
$F$, which encodes a maternal factor that accumulates in the oocytes during oogenesis and which imposes female development on the zygotes derived from them. Androgenic females and males are homozygous for the recessive fallele, which does not produce the maternal factor.

The present manuscript focuses mainly on the insects with different types of sex determination mechanisms for which genetic and molecular data are available. The sex determination genetic cascade of $D$. melanogaster is discussed in the next section, followed by an analysis of the sex determination genes of ther dipteran and non-dipteran insects. Later, representative primary signal are discussed. Finally, some evolutionary aspects of these systems are examined.

\section{The sex-determining genetic cascade of Drosophila}

This section briefly reviews the genetic basis of sex determination in D. melanogaster, an organism for which a coherent picture of sex development is now emerging. This has been made possible thanks to the combination of sophisticated genetic and molecular techniques available for use with this paradigmatic insect. For detailed information on sex determination in D. melanogaster, the interested reader is referred to other reviews (MacDougall et al., 1995; Cline and Meyer, 1996; Schütt and Nöthiger, 2000; Sánchez et al., 2005). For other aspects on sex-determining mechanisms in other organisms see revisions by De Loof and Huybrechts (1998), Lalli et al. (2003) and Manolakou et al. (2006). This revision focuses on sex determination in the somatic component of the animal. The germ line shows sexual dimorphism, as does the somatic tissue. Cells with the $2 X ; 2 A$ chromosomal constitution follow the oogenic pathway, while $X Y$;2A cells develop into sperm. Sex determination in the germ line is not discussed here; the interested reader is referred to the reviews of Cline and Meyer (1996) and Oliver (2002).

In $D$. melanogaster, sex determination is under the control of the gene Sex lethal $(S x)$ (Cline, 1978; reviewed in Penalva and Sánchez, 2003). The epistatic relationships between $S x /$ and the other sex determination genes transformer(tra), transformer-2(tra-2)and doublesex (dsx) have revealed that a hierarchical interaction exists among them (Baker and Ridge, 1980). Their characterisation has shown that sex-specific splicing of their primary transcripts controls their expression during development, the product of one gene controlling the sex-specific splicing of the pre-mRNA of the downstream gene in the cascade (see Fig. 1).

The gene $S x$, which is at the top of this cascade, has two promoters, the so-called early and late promoters (Salz et al., 1989) (see Fig. $2 \mathrm{~A})$. The early promoter functions only in females and responds to the primary genetic X/A 
(ratio of $X$ chromosome to autosomal sets) signal, which is transmitted in 2X;2A (females) but not in XY;2A (males) flies; this controls $S x /$ at the transcriptional level (Torres and Sánchez, 1991; Keyes et al., 1992). Sx/is activated in females but not in males (the $Y$ chromosome plays no role in $S x$ /activation); the result is the production of early Sxl protein in females but not in males. Once the activity of $S x$ is determined, an event that occurs around the blastoderm stage, the $\mathrm{X} / \mathrm{A}$ signal is no longer needed and the activity of $S x /$ remains fixed (Sánchez and Nöthiger, 1983; Bachiller and Sánchez, 1991). The capacity of $S x /$ to function as a stable genetic switch throughout development and during adult life is owed to a positive autoregulatory function of this gene (Cline, 1984); this constitutes the device memory for sex determination. The biological role of the primary genetic X/A signal is therefore to transiently «switch on» the early $S x /$ promoter, providing females with the early Sxl proteins needed to establish female-specific control of $S x /$ once the late constitutive promoter of this gene begins its function. The identification of a set of genes involved in the initial step of $S x /$ activation indicates that a conventional genetic system is at the basis of the X/A signal. To learn more about the molecular nature of this signal, the inter- ested reader is referred to Cline (1993), Cline and Meyer (1996), and Sánchez et al. (1994, 1998, 2005). For a theoretical analysis of the formation of the X/A signal and its effect on $S x$ /activation, see Louis et al. (2003).

After the blastoderm stage, the late $S x /$ promoter begins to function in both sexes, and production of the late $S x$ /transcripts persists throughout the remainder of development and adult life. The male transcripts differ from the female by the inclusion of a male-specific exon that places stop codons in the open reading frame of mature mRNAs. This gives rise to truncated, nonfunctional Sxl proteins. In females, this male-specific exon is spliced out and functional Sxl proteins are produced (Bell et al., 1988; Bopp et al., 1991). Therefore, the control of $S x /$ after the blastoderm stage and throughout development and adult life occurs by the sex-specific splicing of its transcript, such that functional SxI proteins are only produced in females (Fig. 2A). The autoregulatory function of $S x /$ takes place at the level of splicing: the Sxl protein participates in the female-specific splicing of its own primary transcript (Bell et al., 1991).

The female-specific splicing of late $S x /$ pre-mRNA requires, in addition to the SxI protein, the function of other genes, such as

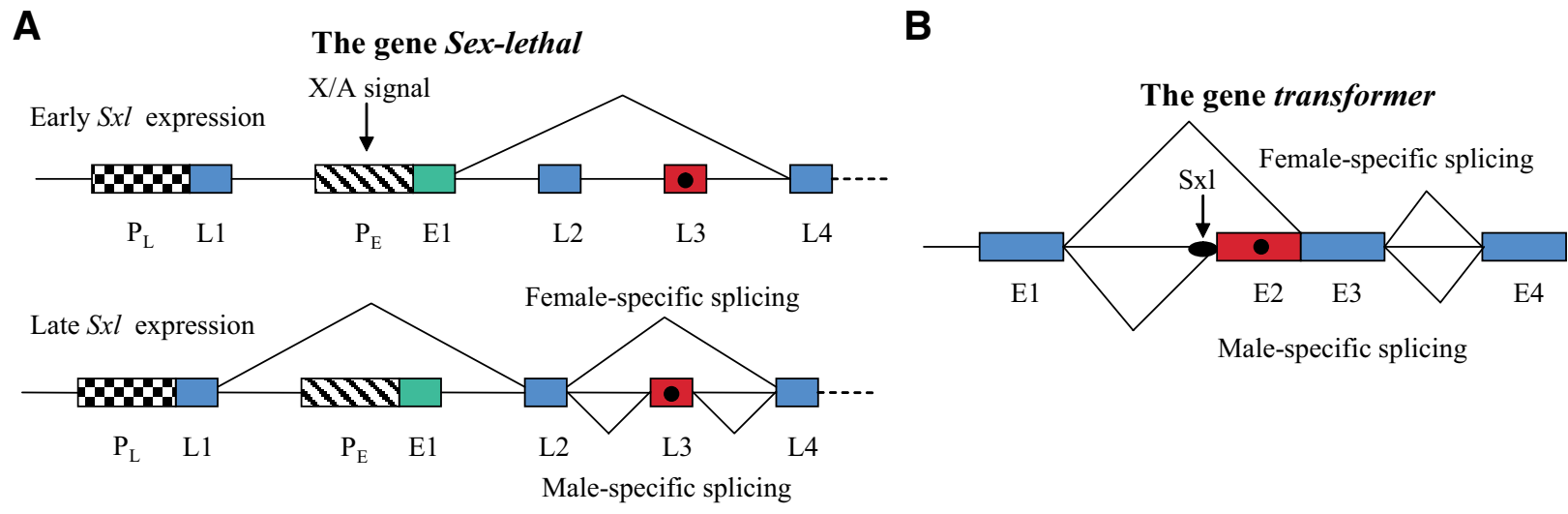

C

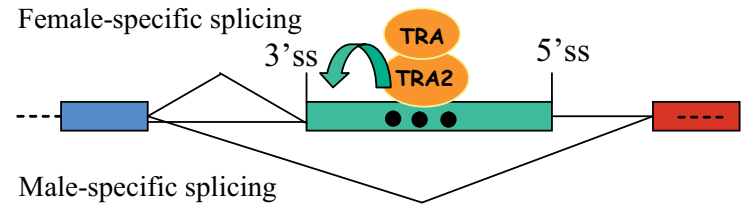

Activation of the 3'ss of female-specific exon

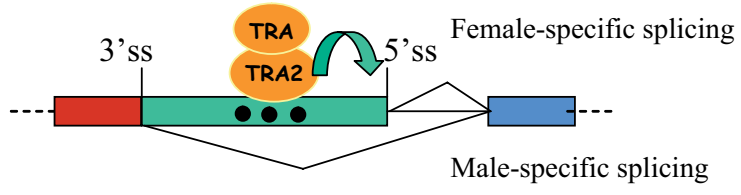

Activation of the 5'ss of female-specific exon

Fig. 2. Sex-specific splicing of $\boldsymbol{S x I}(\mathbf{A})$, tra (B), dsx (C) and fru (D) pre-mRNAs. Boxes and thin lines represent exons and introns respectively. (A) SxI produces two temporally distinct sets of transcripts corresponding to the function of its two early $\left(P_{E}\right)$ and late $\left(P_{L}\right)$ promoters. The $X / A$ signal acts on the early promoter $\left(P_{E}\right)$. The early Sxl primary transcripts follow a fixed splicing pattern in which exon L2 and the male-specific exon $L 3$ (in red) are excluded, and in which the early specific exon 11 (in green) is directly spliced to exon L4. Exon L4 and the exons downstream from it are present in both early and late SxI mRNAs. The dot inside the male-specific exon L3 denotes the presence of translation stop codons. (B) The black ellipse represents the sequence to which both SxI and U2AF proteins bind. The binding of the former prevents the binding of the latter. The dot inside the male-specific exon $E 2$ denotes the presence of translation stop codons. (C,D) The small black balls inside the female-specific exon (red box) denotes the Tra-Tra2 binding sites. This complex activates the 3'splicing site (3'ss) of the female-specific exon in the dsx pre-mRNA, whereas it activates the 5 'ss (the 5' splicing site) of the female-specific exon in the fru pre-mRNA. The blue, red and green boxes represent common and male-and femalespecific exons, respectively. 
sans fille (snf) (Albrecht and Salz, 1993; Flickinger and Salz, 1994; Salz and Flickinger, 1996; Samuels et al., 1998), femalelethal-2-d (fl(2)d) (Granadino et al., 1990; 1996; Penalva et al., 2000; Ortega et al., 2003), and virilizer (vir)(Hilfiker and Nöthiger, 1991; Hilfiker et al., 1995; Niessen et al., 2001). These genes, however, play no role in the splicing pattern of early $S x$ /transcripts (Horabin and Schedl, 1996).

$S x$ /controls the splicing of the pre-mRNA from the downstream gene tra. This gene is transcribed in both sexes, but its RNA follows alternative splicing pathways (Fig. 2B). The trapre-mRNA has two alternative 3' splice sites; one is female-specific and the other non-sex specific. When the latter is used, a non-sex-specific transcript is generated that carries a translation stop codon in the open reading frame, leading to the production of a truncated, nonfunctional Tra protein. In females, approximately half of the tra pre-mRNA is spliced differently, the female-specific 3' splice site being used due to the intervention of the Sxl protein. As a result, the stretch containing the termination codon is not included in the mature transcript and synthesis of full length Tra protein occurs (Boggs etal., 1987; Belote etal., 1989; Válcarcel etal., 1993). The genes fl(2)d(Granadino et al., 1996) and vir(Hilfiker et al., 1995) are also required for female-specific splicing of the trapre-mRNA. Genetic analyses have ruled out a direct role of snf in tra premRNA splicing (Cline et al., 1999).

The Tra product and the product of the constitutive gene tra-2 control the sex-specific splicing of pre-mRNA from the gene doublesex (dsx). This gene is at the bottom of the sex determination cascade and is transcribed in both sexes, but gives rise to two different proteins - Dsx $\mathrm{F}^{\mathrm{in}}$ females and $\mathrm{Ds} \mathrm{X}^{\mathrm{M}}$ in males. These two Dsx proteins are transcription factors that control the activity of the final target genes involved in sexual differentiation. Both proteins share the N-terminal domain, which contains a DNA-binding domain (DM domain). However, they differ in their C-terminal domains, which endow these proteins with their specific function (Burtis and Baker, 1989; Hoshijima et al., 1991). The protein finally produced depends on the result of the sex-specific splicing of the primary transcript (Fig. 2C). Male-specific splicing represents the default mode. The incorporation of the female-specific exon instead of the male-specific exon is caused by activation of the weak female-specific splice acceptor site. This activation is exerted by the binding of the Tra-Tra2 complex to the 13nucleotide repeated sequences (DsxRE), plus the binding of a specific member of the SR family - RBP1 - to the repeats, and finally the binding of dSF2/ASF to the purine-rich element (PRE) in the female-specific exon. This allows the weak female specific 3' splice site to be recognised and used by the generic splicing machinery (Hedley and Maniatis 1991; Hertel et al., 1996; Ryner and Baker, 1991; Tian and Maniatis, 1993).

The Tra product and the product of the constitutive gene tra-2 control also the sex-specific splicing of pre-mRNA from the gene fruitless (fru)(Fig. 2D). This gene, as well as $d s x$, is involved in the male sexual development of the central nervous system (CNS) (Rideout et al., 2007), which is required for male courtship behaviour (Shirangi et al., 2006). It is a complex gene, transcribed in both sexes, with four promoters (P1-P4), which generate multiple types of mRNAs by alternative splicing of the primary transcript. These mRNAs encode different Fru proteins that differ at their C-terminal domain. The Fru proteins have a BTB domain in their $\mathrm{N}$-terminus and, with the exception of some variants, two
Zn-finger motifs in their C-terminus. The male-specific FruM protein is generated from the sex-specifically spliced primary transcript from the P1-promoter. In females, the Tra-Tra2 complex controls the sex-specific splicing of the P1-primary transcript: the binding of this complex to their target sites in the femalespecific exon promotes its inclusion into the mature mRNA. This exon contains translation-stop codons so that in females no FruM protein is produced. In males, where no Tra protein is available, the female-specific exon is spliced out (Ryner et al., 1996; Heinrichs et al., 1998; Goodwin et al., 2000). The P2-P4 promoters function in neuronal and non-neuronal tissues from embryonic stages onward and encode Fru proteins that exert a vital function in both sexes. The function of P1 promoter is restricted to $2 \%$ of neurons in the CNS, in various regions of the brain and ventral ganglia, from late third instar larva onward (reviewed in Billeter et al., 2002; 2006). To this respect, it is worth mentioning that sexual behaviour of the Drosophila male is irreversibly programmed during a critical period extending from shortly before puparium formation into early metamorphosis (Arthur et al., 1998). Sexual behaviour, however, is not reviewed here. The interested reader is referred to Yamamoto et al. (1998), O'Kane and Asztalos (1999), Greenspan and Ferveur (2000) and Billeter et al. (2002; 2006) and references therein.

The gene intersex (ix) is transcribed in both sexes. Its premRNA does not follow sex-specific splicing, indicating that the Ix protein is present in both sexes. Ix interacts with $\mathrm{Dsx}^{\mathrm{F}}$ but not $\mathrm{Dsx} \mathrm{M}^{\mathrm{M}}$, suggesting that $\mathrm{Ix}$ and $\mathrm{Dsx} \mathrm{F}^{\mathrm{F}}$ form a complex to control female terminal differentiation (Chase and Baker, 1995; Waterbury et al., 1999; Garrett-Engele et al., 2002).

The gene hermaphrodite (her)has a dual function. Its maternal expression is necessary for early $S x /$ activation, although its zygotic expression is necessary for female terminal differentiation and some aspects of male terminal differentiation (Pultz and Baker, 1995; Li and Baker, 1998).

\section{Genes homologous to the Drosophila sex determina- tion genes in other dipteran and non-dipteran insects}

Major progress has been made in understanding the developmental processes associated with selected model organisms, among which Drosophila melanogasterhas played a paramount role. Moreover, the past few years have seen a great amount of interest in the evolution of developmental mechanisms at the genetic and molecular levels, and in determining the evolutionary processes by which these mechanisms came into existence. In this respect, sex determination is a process that seems to be exceptionally suitable for comparative study, given the great variety of sex determination mechanisms that exist. Indeed, sex determination has long been of major interest not only as a developmental process but also as an evolutionary problem - a problem that can only be solved once the genetic structures of sex determination pathways have been identified and compared. Molecular genetic technologies now permit such comparisons. In addition, sex determination in the reference system -that of Drosophila melanogaster- is understood in fine detail (as reported above), making truly informative comparisons possible. Data on the evolution of sex-determining mechanisms should provide new insight into how sex determination evolved (and so rapidly). Further, the information obtained is likely to be very important in 
the study of the evolution of other developmental mechanisms, and how these came into existence.

The search for genes homologous to the sex determination genes of $D$. melanogaster has been undertaken (see Fig. 3). Among the genes that form the X/A signal, scute of $D$. subobscura (Botella et al., 1996) and sisterless-a of D. pseudoobscuraand $D$. virilis (Erickson and Cline, 1998) have been characterized. These genes show significant conservation in terms of their structure and function.

\section{The Sex lethal gene}

The $S x /$ gene has been characterised in different Drosophila species, and its structure and sequence organisation determined in D. virilis (Bopp et al., 1996) and D. subobscura (Penalva et al., 1996). As in $D$. melanogaster, $S x /$ regulation occurs by sexspecific alternative splicing: the $S x$ /transcripts in males have an additional exon containing stop translation codons. The $S x /$ of $D$. virilis, however, is unusual given the presence in males of an open reading frame, which encodes an SxI protein, downstream from the last stop codon in the male-specific exon. This is identical to the female SxI protein except for the first 25 amino acids of the amino terminal region, which are encoded by differentially spliced exons. The male Sxl protein predominantly accumulates in the embryonic ectoderm, suggesting it has a role in the development of the central nervous system (Bopp et al., 1996). Sxl protein has also been detected in the males of other species of the virilis radiation ( $D$. americana, $D$. flavomontana, and $D$. borealis) (Bopp et al., 1996).

Outside the genus Drosophila, $S x /$ has been characterised in the dipterans Chrysomya rufifacies (blowfly) (Müller-Holtkamp, 1995), Megaselia scalaris (the phorid fly) (Sievert et al., 1997, 2000) and Musca domestica (the housefly) (Meise et al., 1998), in the tephritids Ceratitis capitata (Medfly) (Saccone et al., 1998) and Bactrocera oleae (olive fly) (Lagos et al., 2005) (all of which belong to the suborder Brachycera), and in Sciara ocellaris (Ruiz et al., 2003), Sciara coprophila, Rynchosciara americana and Trichosia pubescens (Serna et al., 2004), which belong to the suborder Nematocera. $S x /$ has been also characterised in the lepidopteron Bombyx mori (Niimi et al., 2006). The $S x /$ gene of these species is not regulated in a sex-specific fashion, and

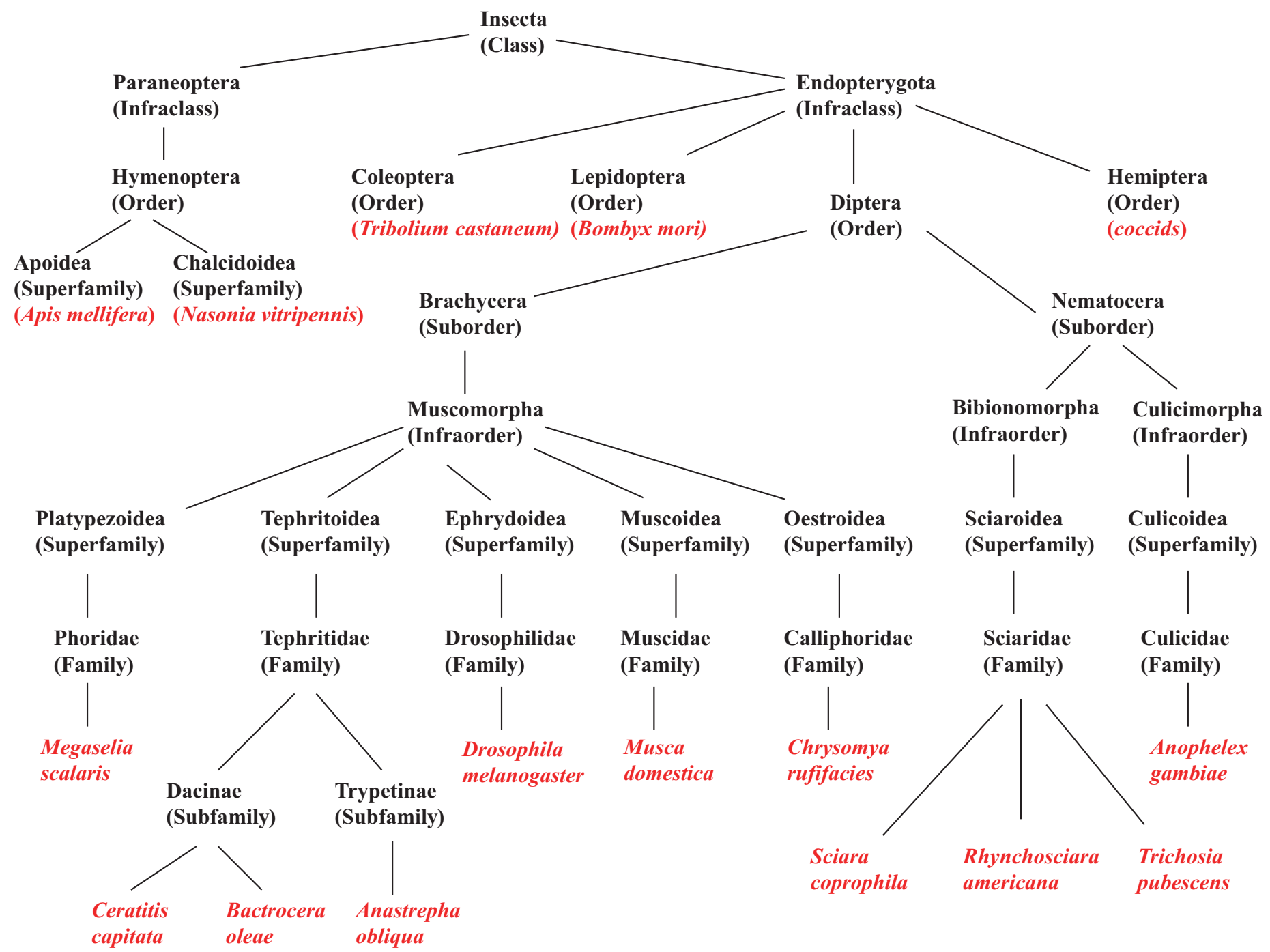

Fig. 3. Classification of the insects mentioned in this article. The species representing a given phylogenetic lineage in the figure is highlighted in red. 
therefore the same $S x /$ transcript encoding the functional Sxl protein is found in both males and females. Thus, in the nondrosophilids, $S x$ /does not appear to play the key discriminating role in sex determination that it plays in Drosophila. This further suggests that $S x$ / has been co-opted to become the master regulatory gene in sex determination during the evolution of the Drosophila lineage.

Questions naturally arise regarding the role of $S x$ /in the nondrosophilids. It has been proposed that outside the drosophilids, the primary or even exclusive function of $S x /$ is to modulate gene activity through inhibition of mRNA translation in both sexes (Saccone et al., 1998). This suggestion is based on the following observations. First, $S x /$ controls dosage compensation in Drosophila through the regulation of translation of the mRNA of gene ms/-2 (Kelley et al., 1997). Second, Sxl protein accumulates at many transcriptional active sites in the polytene chromosomes of females (Samuels et al., 1994). And third, ectopic expression of Ceratitis capitata (Saccone et al., 1998) and Musca domestica (Meise et al., 1998) SxI protein in Drosophila melanogaster is lethal in both sexes, presumably by interfering with certain cellular functions since Drosophila, Ceratitis, and MuscaSxl proteins have conserved RNA-binding domains. In Drosophila melanogaster, the function of gene $S x /$ is only needed in females since males lacking this function are viable and fertile (Cline, 1978).

In the sciarid flies, the SxI protein has been found in polytene chromosome regions of all actively transcribing chromosomes, co-localising with RNA polymerase II but not with RNA polymerase I. This was observed in both sexes (Ruiz et al., 2003; Serna et al., 2004). Moreover, comparison of the different SxI proteins showed their two RNA-binding domains to be highly conserved (Serna et al., 2004). These results agree with the proposition that, in the non-drosophilids, $S x /$ might work as an inhibitor of translation of mRNAs (Saccone et al.,1998). However, the alternative, non-mutually exclusive possibility that Sxl is a general splicing factor cannot be ruled out since both functions are exerted through its two RNA-binding domains. Nevertheless, all the results point to the idea that the ancestral $S x /$ gene was involved in general non-sex-specific gene regulation at the splicing and/or translational levels. Therefore, during the phylogenetic lineage that gave rise to the drosophilids, evolution modified the co-opted $S x /$ gene to convert it into a specific splicing and/or translation inhibitor for controlling sex determination and dosage compensation, profiting from certain properties of the recruited gene that are maintained in the evolved Drosophila Sx/gene.

\section{The transformer gene}

The tra gene of $D$. simulans, $D$. mauritiana, $D$. sechellia, $D$. erecta (O'Neil and Belote, 1992; Kulathinal et al., 2003), D. hydei and $D$. virilis (O'Neil and Belote, 1992) has also been characterised. Its comparison with tra of $D$. melanogaster revealed an unusually high degree of divergence, yet heterologous genes can rescue tra mutations in $D$. melanogaster (O'Neil and Belote, 1992).

Outside the drosophilids, the gene trahas been characterised in the tephritids Ceratitis capitata (Pane et al., 2002), Bactrocera oleae (Lagos et al., 2007) and Anastrepha obliqua (Ruiz et al., 2007a). The putative Tra protein of these tephritids is larger than that of the drosophilids due to an extra tract of amino acids in the $\mathrm{N}$-terminal domain. As in the drosophilids, the gene tra is constitutively expressed in both sexes and its primary transcript shows sex-specific alternative splicing. However, whereas in the drosophilids $S x$ /regulates tra, in the tephritids this gene appears to have an autoregulatory function that produces functional Tra protein specifically in females. The gene train the tephritids have male-specific exons that contain translation stop codons. The incorporation of these exons into the mature tra mRNA in males determines that in these a truncated, nonfunctional Tra protein is produced. In females, the male-specific exons are spliced out because of the presence of Tra protein. The presence of putative Tra-Tra2 binding sites in the malespecific exons and in the surrounding introns suggests that the tephritid Tra and Tra2 proteins form a complex, whose binding to their target sequences prevents the male-specific exons from becoming incorporated into mature tramRNA. The introduction of Ceratitis (Pane etal., 2005) or Bactrocera (Lagos et al., 2007) tra-dsRNA into Ceratitis or Bactrocera embryos, respectively, results in the destruction of endogenous tra function in both species and the subsequent complete transformation of females into fertile males. Moreover, the Ceratitis tra-cDNA encoding the putative full-length Tra protein can strongly transform Cctra transgenic Drosophila melanogaster males into females though this transformation appears to be incomplete (Pane et al., 2005). Pane et al. (2002) proposed that in Ceratitis the gene tra plays a key regulatory role, acting as the memory device for sex determination via its autoregulatory function.

The Tra protein in the tephritids Ceratitis, Bactrocera and Anastrephashows a dual splicing role. On one hand it behaves as a splicing activator of $d s x$ pre-mRNA -the binding of Tra to the female-specific exon promotes the inclusion of this exon into the mature mRNA. On the other hand, Tra acts as a splicing inhibitor of its own pre-mRNA -the binding of Tra to the malespecific exons prevents the inclusion of these exons into the mature mRNA. It has been proposed that the Tra2-ISS binding sites, which have been found in the splicing regulatory region of the tra pre-mRNA, but not in $d s x$ pre-mRNA, of the tephritids provide the distinguishing marker for the dual splicing function of the Tra-Tra2 complex in tephritids (Ruiz et al., 2007a).

\section{The transformer-2 gene}

The gene tra-2 of $D$. virilis has been characterised (Chandler et al., 1997). It encodes a set of protein isoforms analogous to those of $D$. melanogaster, and can rescue tra-2 mutations in this species. Outside the genus Drosophila, tra-2 has been characterised in the housefly Musca domestica (Burghardt et al., 2005). The injection of Musca tra-2 dsRNA into Musca embryos results in the complete transformation of genotypically female embryos into fertile adult males, highlighting the role of tra-2 in Musca sex determination. This gene is transcribed in both sexes and its function is required for the female-specific splicing of Musca dsxpre-mRNA. Genetic data suggest that tra2 participates in the autocatalytic activity of gene $F$ (Burghardt et al., 2005), the key sex-determining gene in the housefly (Dübendorfer et al., 2002).

\section{The doublesex gene}

Outside the drosophilids, the gene $d s x$ has been characterised 
in the dipterans Megaselia scalaris (Sievert et al., 1997; Kuhn et al., 2000), Musca domestica (Hediger et al., 2004), and Anopheles gambiae (Scali et al., 2005), in the tephritids Bactrocera tryoni(Shearman and Frommer, 1998), Bactrocera oleae (Lagos et al., 2005), Ceratitis capitata (Saccone et al., cited in Pane et al., 2002) and Anastrepha obliqua (Ruiz et al., 2005; 2007b), and in the lepidopteran Bombyx mori(Ohbayashi et al., 2001; Suzuki et al., 2001). The molecular organisation of the $d s x$ ORF varies among these insects, but in all cases $d s x$ encodes male- and female-specific RNAs that encode putative male- and female-specific Dsx proteins sharing the N-terminal region but differing in their $\mathrm{C}$-terminal regions (as in Drosophila). The protein finally produced depends on the result of the sex-specific splicing of the primary transcript. In all the dipteran insects, putative Tra-Tra2 binding sites are found in the femalespecific exon, suggesting that, like in Drosophila, male-specific splicing represents the default mode and that female-specific splicing requires Tra protein (which would only be present in females). Unlike in the dipteran insects, the lepidopteran Bombyx $d s x$ does not have a weak female-specific splice site, and does not carry the putative Tra-Tra2 binding sequences. This suggests that the female-specific splicing of $d s x$ pre-mRNA is the default-splicing mode in Bombyx. In the lepidopterans, the heterogametic sex is female ( $Z W)$ and the homogametic sex is male ( $Z Z)$, unlike in the dipterans that show sexual heteromorphic chromosomes: the homogametic sex is female $(X X)$ and the heterogametic sex is male (either $\mathrm{XY}$ or $\mathrm{X} 0$ ).

\section{The fruitless gene}

The gene fru of $D$. simulans, D. yakuba, D. pseudoobscura, $D$. virilisand D. suzukii(reviewed in Billeter et al., 2002) and that have Anopheles gambiae and Tribolium castaneum (Gailey et al., 2006) has been characterised. In all the cases, the gene fru show a conserved molecular structure and the male-specific FruM protein arise by conserved mechanisms of sex-specifically activated and alternative exon splicing, which is controlled by transformer. Moreover, the ectopic expression of $A$. gambiae $\mathrm{Fru}^{\mathrm{MC}}$ in $D$. melanogasterwas sufficient to rescue the muscle of Lawrence (MOL)-less phenotype-fru ${ }^{3}$ mutant males and to induce the formation of a MOL-like muscle in females (Gailey et al., 2006). The MOL in D. melanogasteris under the control of frugene (reviewed in Billeter et al., 2002, and cites therein).

\section{The intersex gene}

The gene ix has been characterised in the dipterans $D$. virilis and Megasela scalaris, and in the lepidopteran B. mori(Siegal and Baker, 2005). The Ix proteins appear to have a conserved organisation. The amino-terminal region is rich in glutamine, proline, glycine and serine residues, a feature of known transcription regulators. The carboxy-terminal region contains a high proportion of polar amino acids and two conserved phenylalanine residues, which appear to be specific to the Ix proteins. The $D$. virilis and the $M$. scalaris ix genes fully restore the ix function in otherwise ix mutant $D$. melanogasterflies, suggesting that these Ix homologs can interact with the DrosophilaDsx ${ }^{F}$ protein just as Drosophilalx protein does. However, the $B$. mori ix gene only partially rescues female sexual development of Drosophila ix mutant females. This suggests that Dsx $\mathrm{F}$ and Ix proteins co-evolved, and that sufficient time has elapsed since the moment of separation of the lepidopteran and dipteran lineages to allow the accumulation of divergence between the Dsx $F$ and Ix proteins of these species (Siegal and Baker, 2005).

\section{The complementary sex determination system (CSD)}

In some hymenopteran insects, such as wasps, sawflies, ants and bees, gender is regulated by haploidy/diploidy: males are haploid and develop from unfertilised eggs, whereas females develop from fertilised eggs. In these insects, the sexual pathway followed by the zygote depends on a primary signal based on the presence of either one or two different alleles of a single gene at the so-called complementary sex determiner (csd) locus. Males are hemizygous and females are heterozygous at this locus. Infertile diploid males may arise when this locus is homozygous (Cook, 1993).

The work of Beye et al. (2003) provided a breakthrough in the understanding of the genetic basis underlying this haploid/diploid sex determination mechanism. These authors isolated the csd gene of the honeybee $A$. mellifera. This gene encodes an arginine-serine rich (SR) protein, with structural similarity to the dipteran transformergenes. The gene $c s d$ is transcribed in both sexes but has a highly variable region -responsible for the allelic variation that characterises this locus- giving rise to the production of different Csd isoforms. It is thought that allelic heterozygosity produces two functional Csd protein isoforms capable of forming a complex that determines female development, whereas hemizygosity, or allelic homozygosity, generates a single Csd protein isoform that cannot generate a functional complex, thus determining male development (Beye et al., 2003; Beye, 2004) (see Fig. 4).

The CSD system does not apply to other hymenopteran insects, such as Nasonnia vitripennis, which belong to the parasitoid wasp group Chalcidoidea, because homozygous diploids develop into females (reviewed in Beukeboom et al., 2007 and cites therein). A new model has been put forward to explain sex determination in these parasitoid hymenopterans (Beukeboom et al., 2007). The MEGISD model (for Maternal Effect Genomic Imprinting Sex Determination) proposes that the sex of the zygote depends on the activity of the zygotic sex determiner (zsd) gene, whose function determines female development. A maternal effect gene ( $m s d$ ) causes imprinting of the zsd gene during oogenesis so that the female-inherited $z s d$ allele is not active in the zygote. Consequently, haploid zygotes develop as males because they carry the imprinted $z s d$ allele inherited from the mother. Diploid zygotes develop as females because the paternally inherited $z s d$ is not imprinted and then becomes expressed. For more details see Beukeboom et al. (2007).

\section{Sex determination mechanisms based on $\mathrm{X}$ chromo- some elimination: the sciarid system}

In most of the species, the sex of an individual is fixed at fertilisation. However, in some cases the chromosomal differences determining gender are brought about by specialised behaviour of the $X$ chromosomes during the first stages of embryonic development. This is the case of the dipteran families Cecydomyiidae (White, 1973; Stuart and Hatchett, 1991) and Sciaridae (DuBois, 1933; Metz, 1938), which belong to the subor- 


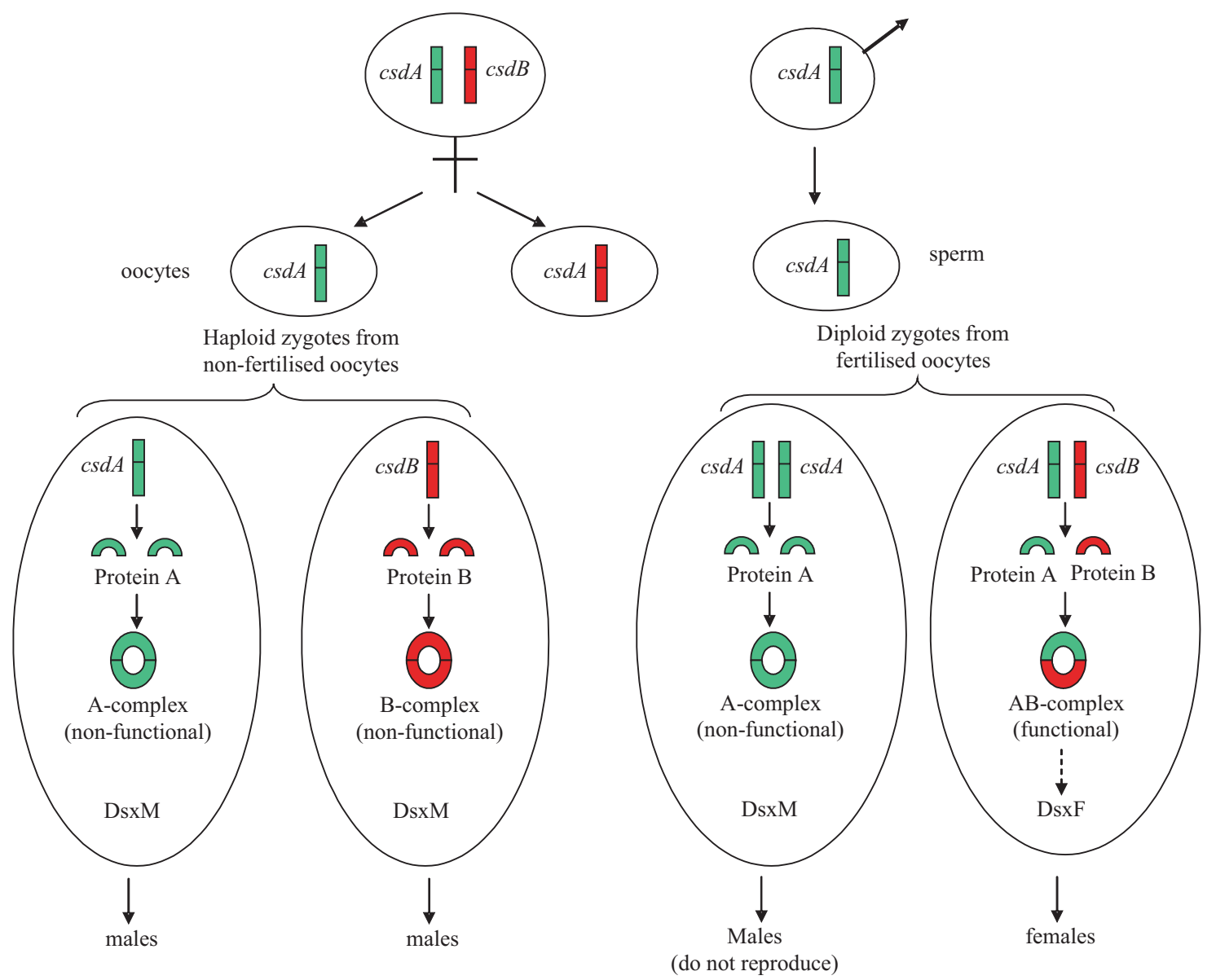

Fig. 4. Sex determination in the honeybee Apis mellifera. The green and red segments represent the chromosomes carrying the complementary sex determination (csd) locus. CsdA and csdB stand for two alleles of this locus, which encode two Csd protein isoforms, protein A and B respectively. Modified from Beye (2004).
Among the sciarids there are some species in which the females produce offspring of only one sex - the unisexual (or monogenic) species. These females are either androgenic (male producers) or gynogenic (female producers). Some species are bisexual (digenic or amphigenic), i.e., the progeny is composed of a mixture of males and females. The sex ratio (number of males vs. females) of the progeny of each female, however, is highly variable, deviating from 1:1. Nevertheless, at the level of the whole population, the sex ratio follows a normal distribution around this value (Metz, 1938).

In the case of the monogenic species Sciara coprophila, gynogenic and androgenic females differ in the presence of a special X' chromosome in the former: these females are $X ' X$, whereas der Nematocera.

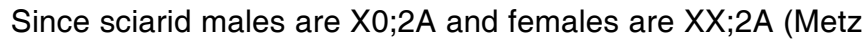
and Schmuck, 1929), the primary genetic signal that triggers sex determination appears to be the ratio of $X$ chromosomes to sets of autosomes (X/A ratio), as in Drosophila. There is, however, a fundamental difference in the way the $X / A$ chromosomal signal is formed. In Drosophila, embryos are either $2 \mathrm{X} ; 2 \mathrm{~A}$ or $\mathrm{XY} ; 2 \mathrm{~A}$, a direct consequence of the chromosomal constitution of the gametes: oocytes are $X ; A$, and sperm are either $X ; A$ or $Y ; A$. In sciarids, oocytes are $X ; A$ and sperm are $2 X ; A$ (see Fig. 5). Consequently, Sciaraembryos start development with two sets of autosomes and three $X$ chromosomes (3X;2A), two of which are sister chromatids of paternal origin (Metz, 1938). When the zygotic nuclei reach the egg cortex, one paternal $X$ chromosome is eliminated in the somatic cells of embryos destined to be females $(2 X ; 2 A)$ and two are eliminated in those destined to become males (X;2A) (DuBois, 1933; Perondini et al., 1986). Therefore, in the formation of the $\mathrm{X} / \mathrm{A}$ chromosomal signal in sciarids an "imprinting" process must occur in one of the parents, which determines that the chromosomes to be eliminated are of paternal origin. Historically, the term "imprinting" was coined to describe selective identification of paternal chromosomes in sciarids (Crouse, 1960). androgenic females are $X X$ (see Fig. 6). The $X X$ females produce only X0 males, which do not receive the $X$ ' chromosome. The gynogenic females produce both gynogenic and androgenic females. The system functions as if regulated by a pair of alleles, the $X$ 'X and XX females being produced in a 1:1 ratio (Moses and Metz, 1928; Metz and Schmuck, 1929; Metz, 1938; Gerbi, 1986). There is an inversion in the $X^{\prime}$ chromosome that prevents its recombination with the homologous $X$ chromosome, thus retaining in the $X^{\prime}$ the factor for female production (Crouse, 1960). Thus, the elimination of the paternally-derived chromosome is maternally controlled. The gynogenic females produce two classes of oocytes carrying oocytes are pre-determined to eliminate one $X$ chromosome of the two inherited from the father. The X'- and X-oocytes contribute to the production of the gynogenic and androgenic females (respectively) of the following generation. The $X X$ androgenic females produce a unique class of $X$-oocytes without the maternal factor involved in $\mathrm{X}$ chromosome elimination; therefore these oocytes are pre-determined to eliminate the two $X$ chromosomes inherited from the father. Consequently, the $\mathrm{X}$-oocytes from the androgenic females contribute to the production of $\mathrm{XO}$ males of the following generation. either the X' or the X chromosome. Both contain the maternal factor that controls $X$-chromosome elimination, thus these two types of 
Sciara ocellaris is a digenic species in which the sex of the offspring is also determined by the female parent through the production of oocytes that contain - or do not contain - the maternal factor for X chromosome elimination (Liu, 1968). In this species the offspring are composed of male and female individuals, but the sex ratio varies widely (Metz, 1938; Davidheiser, 1943; Mori et al., 1979). It has been shown that this variation depends on temperature: at $18-20^{\circ} \mathrm{C}$, the sex ratio distribution, although variable, shows a median at approximately $50 \%$, but at $24-29^{\circ} \mathrm{C}$ the sex ratio moves towards the production of more females. This change in sex ratio is not caused by a higher mortality among males, but by a transformation of male into females (Nigro, 1995; Campos et al.,
1996; Nigro et al., 2007). This increase in female production is due to an increase in the number of embryos that eliminate one instead of the two paternally-derived chromosomes. Temperature-shift experiments have shown that the temperature-sensitive period for the determination of the final sex ratio is from the mid-pupa stage to the emergence of the adult females (Nigro, 1995; Nigro et al., 2007), the period during which oogenesis takes place (Berry, 1941). It should be recalled that in Sciara females the number of oocytes is fixed during the early larval stages and that no further mitosis occurs nor are new oocytes produced in the pupal/adult stages (Berry, 1941).

Spontaneous deviations and mistakes in X-chromosome elimi-

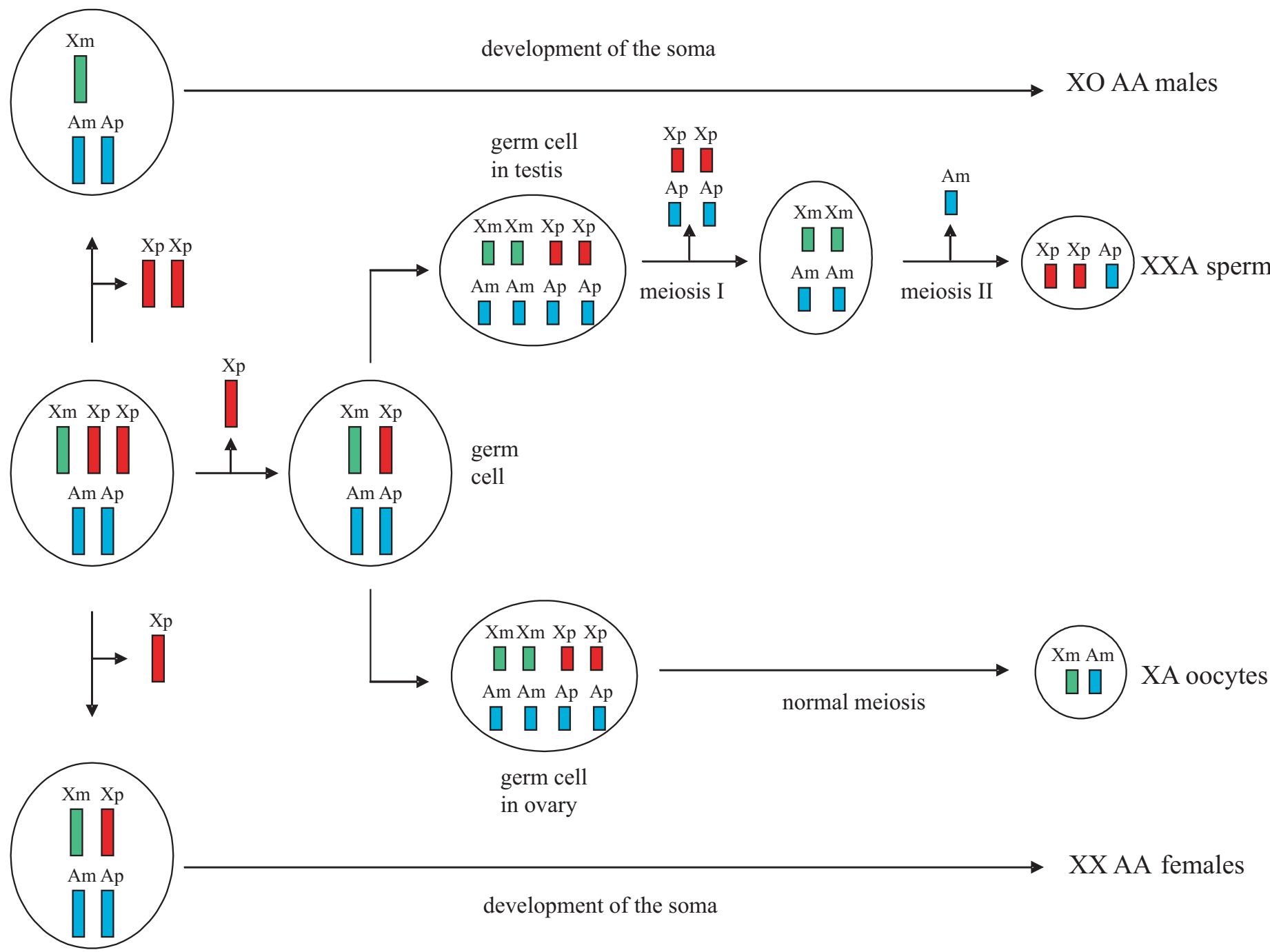

Fig. 5. Diagram of chromosome behaviour in sciarid flies. $X$ stands for the $X$ chromosome and $A$ for the autosomes; $m$ and $p$ denote maternal or paternal origin. The pole cells, which are set apart at the 4th cleavage (DuBois, 1932; Berry, 1941; Perondini et al., 1986), do not eliminate X chromosomes at the same time as the nuclei in the somatic regions of the embryos. Elimination of one paternally-derived $X$ chromosome occurs later, at the beginning of germ band segmentation; just one of the two paternalX chromosomes is eliminated in both male and female embryos (Berry, 1941 ; Rieffel and Crouse, 1966; Perondini and Ribeiro, 1997; Perondini, 1998). Meiosis is highly specialised in males, showing elimination of the paternally derived genome (1st division), and the non-disjunction of the two X chromatids and elimination of one chromatid of each autosome during the 2 nd division. The chromosomes undergoing elimination during both meiotic divisions are segregated and discarded in a cytoplasmic bud (Esteban et al., 1997). The end result is that the functional spermatids and ensuing sperm are of a unique type and contain a haploid set of autosomes and two $X$ chromosomes, all of maternal origin (Gerbi, 1986; Fuge, 1994; Esteban et al., 1997; and references therein). The paternal X chromosomes that are eliminated in each generation are maternal in the previous generation; i.e., the imprinting mark that determines the origin of the chromosomes that are eliminated is erased (or modified) in each generation. Modified from Sánchez and Perondini (1999) and from Goday and Esteban (2001). 


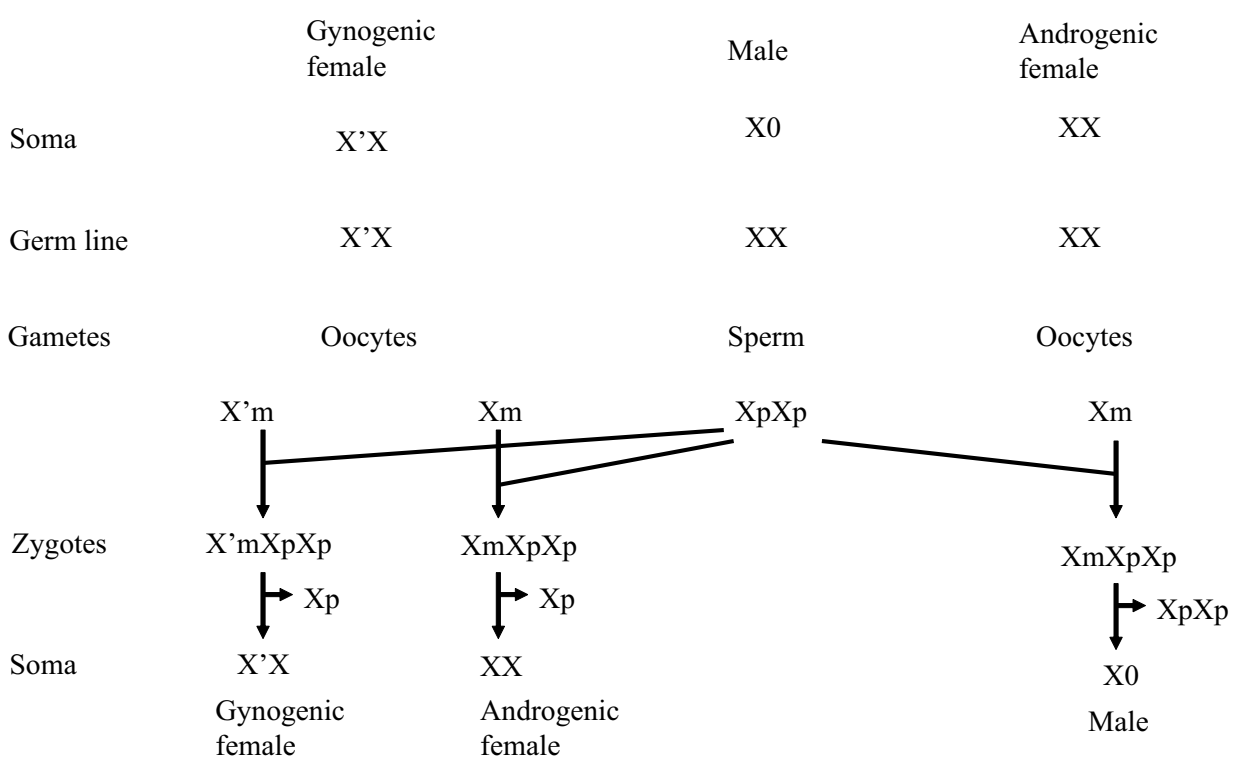

Fig. 6. The production of gynogenic and androgenic females, as well as males, in Sciara coprophila. The maternal and paternal origin of the chromosomes is denoted by $m$ and $p$ respectively.

nation can occasionally occur in the sciarid chromosomal system (for details see Sánchez and Perondini, 1999). Two basic types of error are seen (see Fig. 7): 1) Quantitative errors, involving the number of paternally-derived $X$ chromosome that are eliminated (i.e., some zygotic nuclei of embryos derived from oocytes predetermined to eliminate one $X$ chromosome end up eliminating the two X-paternally derived chromosomes instead). These quantitative errors produce gynandromorphs - individuals with some portions of the body typically male (X0) and others typically female (XX). 2) Qualitative errors, in which the X chromosome eliminated is the one inherited from the mother rather than either of the two inherited from the father. This type of error leads to mosaic flies, either male or female, bearing a mixture of tissues with the normal chromosome set plus tissues patroclinous for the $\mathrm{X}$ chromosome (see Fig. 7).

Errors in X-chromosome elimination have been experimentally induced by the UV irradiation of embryos (Perondini et al., 1987; Guatimosin and Perondini, 1994). The UV doses used did not penetrate more than a few micrometers into the cytoplasm and therefore had little effect on egg survival. Two stages of development were irradiated: 1 ) the early cleavage stage, when only the cytoplasm of the insect egg was affected by the UV radiation (the nuclei remained deep in the endoplasm and were thus shielded), and 2) the syncytial blastoderm stage, by which time the nuclei have migrated to the periplasm and thus both the cytoplasm and the nuclei were UV targets. Irradiation during the cleavage state produced gynandromorphs, i.e., individuals with quantitative errors, while irradiation during the syncytial blastoderm stage produced both gynandromorphs and mosaics, i.e., individuals with quantitative and qualitative errors. Both types of errors were reversed after photoreactivation treatment of the UV-irradiated embryos (Guatimosin, 1996).

The conclusions drawn on the mechanism of X-chromosome elimination derived from the analysis of spontaneous or induced errors are summarised below (for more details see Sánchez and Perondini, 1999; and references therein).

1) The mechanism of $X$-chromosome elimination is similar in monogenic and digenic species.

2) A maternal factor is produced during oogenesis, which collects in the oocyte and then governs the elimination of the $\mathrm{X}$ chromosome in the developing zygote.

3) The embryo eliminates either one or two Xp chromosomes independently of the number of $X$ chromosomes initially present in the zygote.

4) There are two independent mechanisms involved in the elimination of $X$ chromosomes. One regulates the number of $X$ to be eliminated, and resides in the cytoplasm, the other identifies the $X$ to be eliminated, and seems to be nuclear.

5) Among the embryos produced by gynogenic mothers, errors more frequently occur in XXX zygotes that develop into androgenic females than in $X^{\prime} X X$ zygotes that become gynogenic females.

6) Errors are rare in XXX embryos produced by androgenic females.

We have proposed a model for the control of differential Xchromosome elimination in sciarid flies, based on the following assumptions:

1) A chromosomal factor (CF) binds to the paternal $X$ chromosome causing its elimination. This factor is produced in limiting amounts and at similar concentrations in both male and female embryos. Whether CF is maternal or zygotic is irrelevant.

2) A maternal factor (MF) determines the number of paternal $X$ chromosomes to be eliminated. This maternal factor interacts with $\mathrm{CF}$, inactivating it, so that the CF-MF complex cannot interact with the paternal $X$ chromosome. Therefore, the number of $X$ chromosomes eliminated depends on the amount of free $\mathrm{CF}$, which in turn depends on the amount of MF.

3) Imprinting, in relation to the identification of the $X$ chromosome to be eliminated, occurs in the maternal chromosomes and not in the paternal counterparts. The imprinted state is manifested by the inability of the maternal $X$ chromosome to bind $\mathrm{CF}$; consequently, this chromosome cannot be eliminated.

This model is compatible with the basic features of the sciarid chromosomal system, some of which are outlined here (the interested reader can find a more detailed discussion in Sánchez and Perondini, 1999): MF.

1) Sex is controlled by a maternal factor - the above-mentioned

2) Gynogeny and androgeny. The X' chromosome carries a constitutive MF allele. Gynogenic X'X females only produce oocytes with high levels of MF, the embryos derived from these develop into females (i.e., one Xp chromosome is eliminated). In contrast, XX androgenic females carry a weak (or amorphic) MF allele, so they only produce oocytes with low levels of MF (or none at all) and thus give rise to embryos that develop into males (i.e., 
the two Xp chromosomes are eliminated).

3)Quantitative errors in X-chromosome elimination: production of gynandromporphs. The increased frequency of gynandromorphs after UV-irradiation of embryos destined to be females is explained by the destruction of MF. Consequently, a larger amount of free $C F$ will be available to bind the two - instead of one - Xp chromosomes, producing the X0 cells of gynandromorphs. Since MF is located in the cytoplasm, these gynandromorphs can be induced at both the cleavage and syncytial blastoderm stages.

4) Qualitative errors in X-chromosome elimination: production of male and female mosaics. The production of these mosaics is explained in that UV irradiation modifies the imprinting mark of the maternal $X$ chromosome, which then binds with CF and is eliminated. These mosaics are only produced when UV irradiation occurs at the syncytial blastoderm stage, because it is during this stage when the nuclei reach the periphery of the egg and become exposed. The generation of mosaics argues in favour of the imprinting of the maternal, rather than the paternal, $\mathrm{X}$ chromosome.

The question arises as to whether it is necessary to assume the existence of two factors, MF and CF, instead of only one, MF, as proposed by de Saint-Phalle and Sullivan (1996). In their one- factor model, it is assumed that the maternal factor promotes, rather than prevents, the segregation of the Xp chromosome. This maternal factor would directly interact with the Xp chromosome to promote separation of its sister chromatids, whereas neither the $\mathrm{Xm}$ nor the autosomes need this separation factor for normal segregation. This implies that imprinting, in relation to the identification of the $X$ chromosome to be eliminated, occurs in the $X p$ chromosome. The imprinted state in this case is manifested by the requirement of this chromosome to bind the separation factor. This model does not, however, explain the existence of mosaic sciarids.

\section{Sex determination mechanisms based on chromosome elimination or heterochromatisation: the coccid sys- tem}

The coccids (scale insects) belong to the order Homoptera. Sex determination in primitive coccids is usually decided by the XX (female) - X0 (male) sex chromosome mechanism. However, in some groups the sex of an individual is not fixed at fertilisation - as in the sciarids. The differential inactivation and/or elimination of chromosomes as a mechanism of sex determination has been

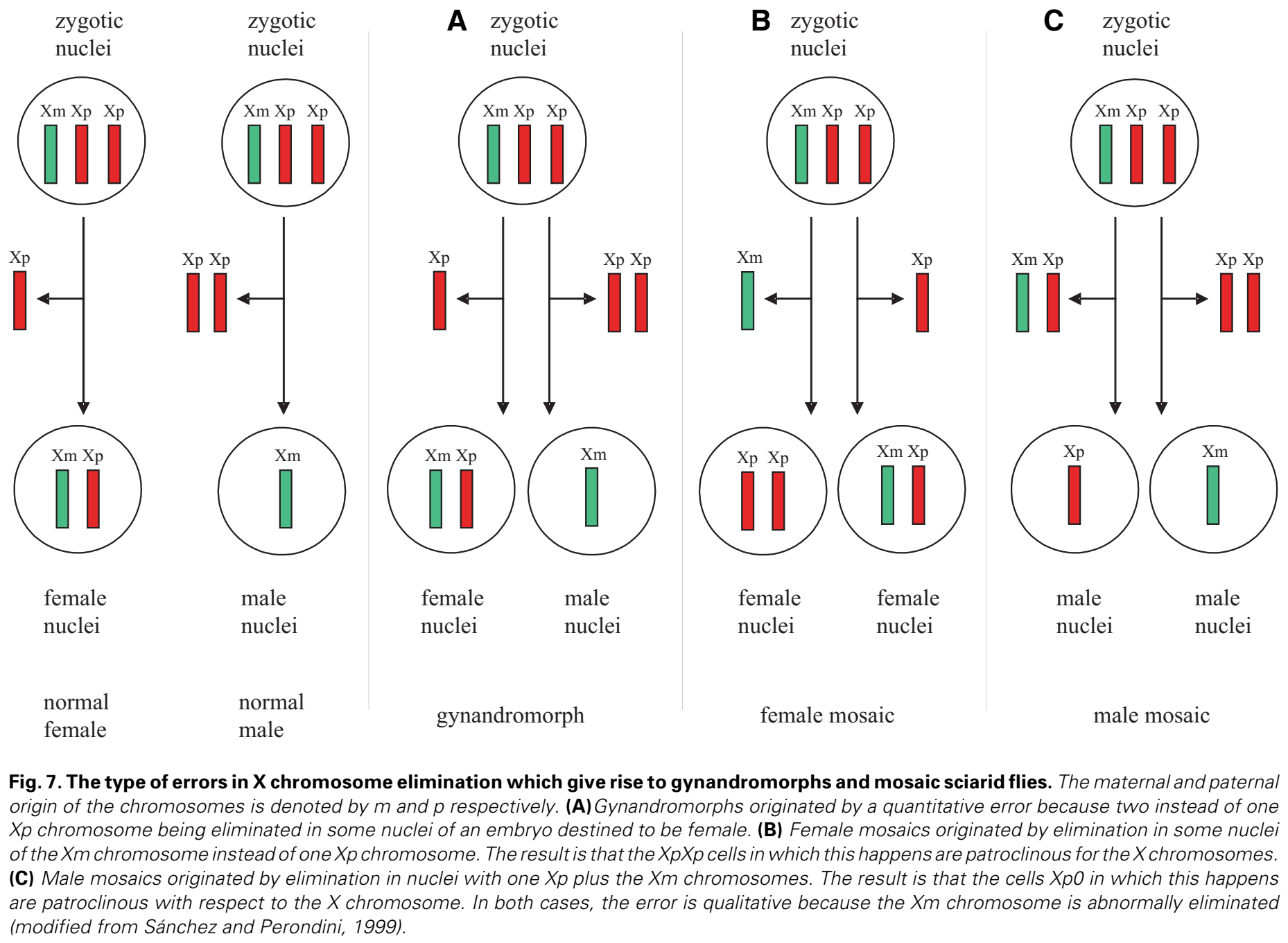

zygotic

female nuclei

normal

female male

normal

male
A zygotic

female nuclei male nucle female nuclei

female mosaic
C zygotic

male male nuclei

Fig. 7. The type of errors in $\mathbf{X}$ chromosome elimination which give rise to gynandromorphs and mosaic sciarid flies. The maternal and paternal origin of the chromosomes is denoted by $m$ and p respectively. (A) Gynandromorphs originated by a quantitative error because two instead of one Xp chromosome being eliminated in some nuclei of an embryo destined to be female. (B) Female mosaics originated by elimination in some nuclei of the Xm chromosome instead of one Xp chromosome. The result is that the XpXp cells in which this happens are patroclinous for the X chromosomes. (C) Male mosaics originated by elimination in nuclei with one Xp plus the Xm chromosomes. The result is that the cells XpO in which this happens (modified from Sánchez and Perondini, 1999). 
reported (Brown and Nur, 1964; White, 1973; Brown and Chandra, 1977; Miller and Kosztarab, 1979; Herrick and Seger, 1999; and references therein). Among the different sexual chromosome systems found in the coccids, the two most paradigmatic are discussed: the lecanoid and the diaspidid systems (Fig. 8). Reproduction in both cases is purely sexual.

Sex determination in the lecanoid coccids is based on a functional haploidy/diploidy mechanism. At the cleavage stage, immediately following fertilisation, all the chromosomes of the embryo are euchromatic. Later, the chromosomes inherited from the father become heterochromatic in embryos destined to be males. In the female embryo, none of the chromosomes become heterochromatic. Thus, females have two functional chromosomal complements, while males are structurally diploid but functionally haploid. In the females, both sets of chromosomes remain active not only during development but also in oogenesis, (the orthodox system). In the males, the heterochromatic set remains inactive. Spermatogenesis is characterised by inverse meiosis and the lack of chromosome pairing and genetic recombination. The first meiotic division is equatorial (disjunction of the sister chromatids), while the second is reductional (disjunction of the maternal and paternal homologs). The result is the formation of the expected four nuclei, two of which are euchromatic and two of which are heterochromatic. Only the euchromatic nuclei undergo spermiogenesis to form functional sperm. The heterochromatic nuclei do not form sperm and disintegrate.

The Comstockiella have a similar mechanism, which differs from the former in that one chromosome of the heterochromatic set remains heterochromatic during spermatogenesis; the remainder of the heterochromatic set is eliminated before prophase. This single heterochromatic chromosome is later eliminated so that the sperm only transmit maternal chromosomes (reviewed in Brown, 1977; Miller and Kosztarab, 1979; Herrick and Seger, 1999; and references therein).

Sex determination in the diaspidid coccids is also based on a haploid/diploid mechanism. In the female embryo both chromosomal complements (one inherited from the mother and one from the father) are functional. In embryos destined to be males, all the chromosomes inherited from the father are eliminated, rendering them structurally and therefore functionally haploid. In the females, oogenesis is orthodox. Spermatogeneis, however, is unorthodox since the paternal chromosomes are absent and the second meiotic division does not occur. Sperm cells carrying a set of the maternal chromatids are therefore produced.

Coccids

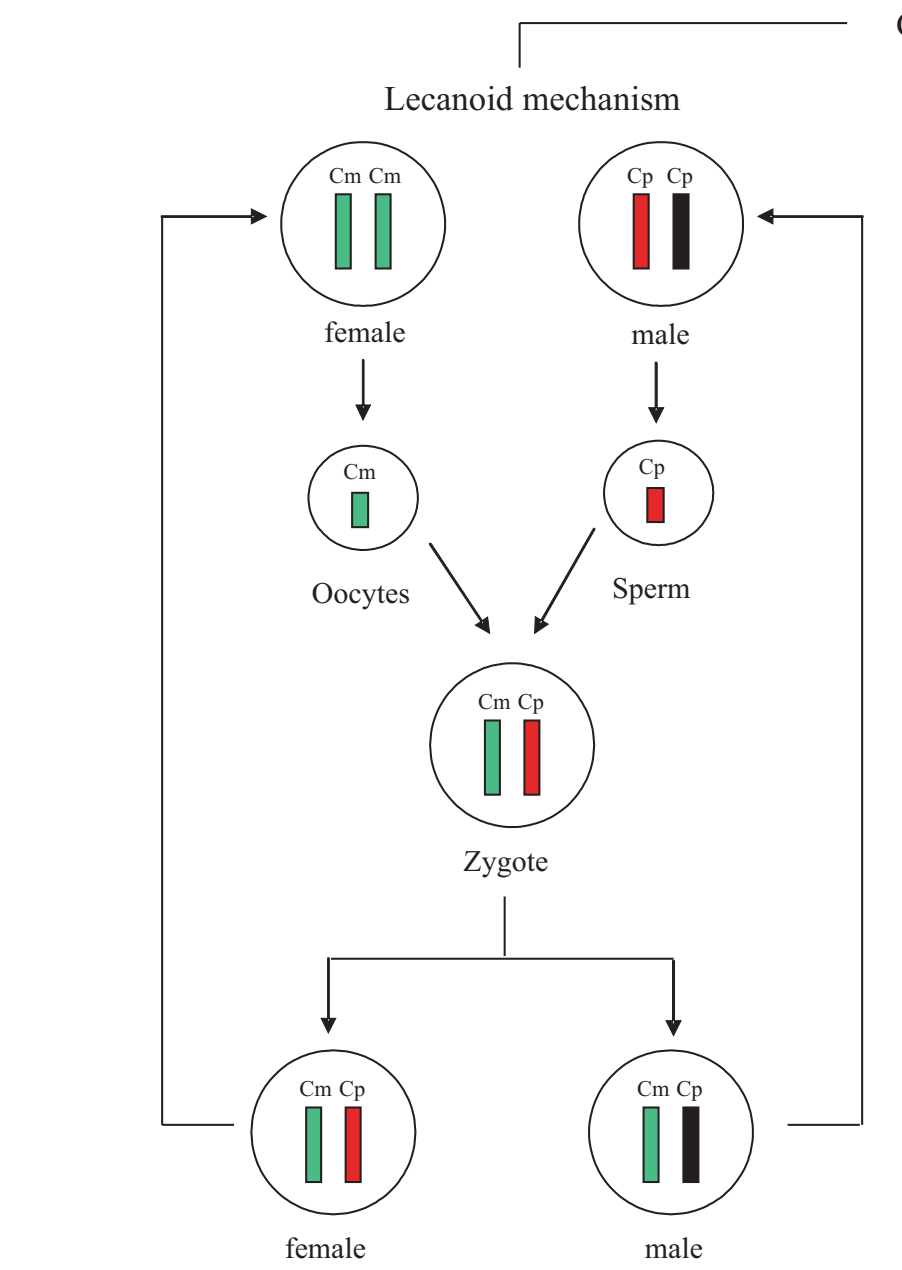

\section{Lecanoid mechanism}

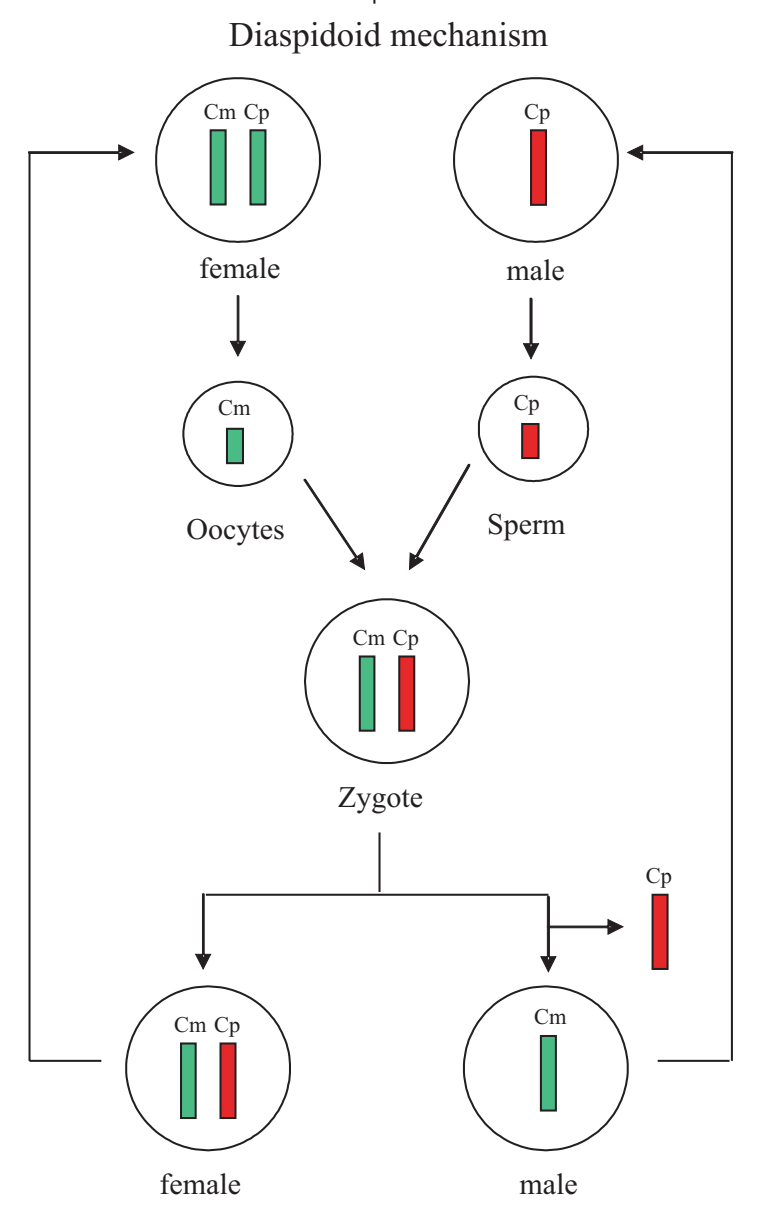

Fig. 8. The chromosome cycle in lecanoid and diaspidid coccids. Each box represents a haploid chromosome complement (C) inherited from the mother $(\mathrm{Cm})$ or from the father $(\mathrm{Cp})$. The black colour in the lecanoid mechanism symbolises the heterochromatic, genetically inert, chromosomal state. 
The following summarises some features of the lecanoid and diaspidid mechanisms relevant to sex determination. For further details see Brown and Nur (1964), White (1973), Brown and Chandra (1977), Miller and Kosztarab (1979), Herrick and Seger (1999) and references therein.

Coccid chromosomes are holocentric. After irradiation of male parents, all of the chromosome fragments in their eventual male offspring are heterochromatic; after irradiation of eventual mothers, all are euchromatic. Therefore, there cannot be a single locus or restricted region on each chromosome that regulates the induction of heterochromatisation (Brown and Nelson-Rees 1961; Nur 1990).

The sex ratio of the offspring of female coccids can fluctuate widely and is subject to environmental influence (Nelson-Rees, 1960). Aging the females before allowing them to mate alters the sex ratio in favour of males - a phenomenon not caused by any differential increase in the mortality of female zygotes. Rather, this is explained by changes in sexual dichronism (i.e., the deposition of male and female embryos at different times during oviposition), the pattern of which can be altered by maternal aging (James, 1937, 1938; Brown and Bennett, 1957; Nelson-Rees, 1960).

Some parthenogenic coccids are known to produce male or female embryos depending upon whether or not the heterochromatisation of one chromosomal set occurs. Nevertheless, the proportion of male to female embryos is very low (about $5 \%$ males and $95 \%$ females are produced); abnormal or degenerating embryos are often observed, which are almost certainly males. Since heterochromatisation naturally occurs in these coccids, no prior passage of the chromosomes through spermatogenesis is required (Nur, 1963).

In experimentally produced haploid embryos and haploid mosaics, the single chromosome set inherited from the father first undergoes heterochromatisation but later becomes euchromatic. The maintenance of the paternally-derived heterochromatic chromosomes requires the presence of the maternally-derived euchromatic chromosome set (Nur, 1962; Chandra, 1963). However, the suppression of heterochromatisation requires no interaction between homologous chromosomes. When a chromosome is lacking from either set in an embryo, its homologue in the other set shows the typical features of the set to which it belongs (Chandra, 1962).

Together, all this evidence suggests that the genome of the mother determines the heterochromatisation (lecanoid) or elimination (diaspidid) of the inherited paternal chromosomes in coccid embryos. In addition, both the lecanoid and diaspidid mechanisms have an associated imprinting process to distinguish between the maternal and paternal chromosomes. This chromosome behaviour is similar to that seen with respect to the elimination of the paternal $X$ chromosome in sciarid flies. Hence, it is proposed here that the model for the control of differential $X$ chromosome elimination in the sciarids mentioned above can be applied to the heterochromatisation or elimination of paternal chromosomes in coccids. According to this model, heterochromatisation or elimination is controlled by a maternal factor, with the maternally-derived chromosomes imprinted so that they do not suffer either fate. For the sake of simplification, it is assumed that the maternal factor exerts its effect through direct interaction with the paternally-derived chromosomes to promote their heterochromatisation or elimination. From the molecular point of view, the female therefore produces two classes of oocyte, one with and one without maternal factor. The first will give rise to males whereas the second will produce females. The imprinted state could mean that the maternally-derived chromosomes do not bind the maternal factor, or that they bind it with much lower affinity than do the paternally-derived chromosomes. In zygotes developing in the latter scenario, the maternally- and paternally-derived chromosomes compete in terms of binding the maternal factor -which is preferentially bound to the paternal set. If the binding of the maternal factor follows a co-operative mechanism, the heterochromatisation or elimination of the paternallyderived chromosomes would be favoured whenever the amount of maternal factor is limited.

According to the proposed model, the females produce two classes of oocyte, those which contain maternal factor - and which are pre-determined to heterochromatise or be eliminated, and those without maternal factor, which are pre-determined not to permit any chromosome to follow either such course. The effect of the temperature or the age of the mother on the offspring sex ratio is explained by a change in the ratio of oocytes with and without maternal factor.

The existence of parthenogenic coccids that produce some male embryos supports the assumption of the model that imprinting occurs in the females, and that the imprinted state of the maternally derived chromosomes is made manifest in their incapacity to become heterochromatic. If heterochromatisation requires the chromosomes to pass through spermatogenesis, then the formation of parthenogenetic male embryos would not be expected - in contrast to that observed. Such male embryos carry only maternally-derived chromosomes. Since all of them are imprinted they should all compete equally for binding with the maternal factor, although this binding would be very much impeded because of the imprinting mark. This explains the low frequency with which parthenogenetic male embryos are seen. The probability that a complete haploid set of chromosomes should become heterochromatic is very low, and in the majority of cases the embryo would be aneuploid. Consequently, the frequency of male offspring derived from parthenogenic females is very small, and abnormal and degenerating embryos are frequently observed.

Two temporal relationships may exist between heterochromatisation (or elimination) and sex determination in coccids: either sex determination precedes heterochromatisation or heterochromatisation occurs prior to sex determination. The first relationship implies that the gender of the embryo is determined first: if it is male, heterochromatisation of a haploid set of chromosomes ensues; if it is female, no heterochromatisation occurs. But in this scenario no difference in the primary genetic signal for sex determination can exist between the diploid embryos that will become female, and those diploid embryos that will develop along the male pathway. It could be argued that the females could produce two classes of oocytes depending on whether or not they carry a male sex-determining factor. In this case, the embryos derived from oocytes carrying the proposed factor would develop into males and heterochromatisation would follow. However, this cannot explain the existence of male embryos produced by parthenogenic coccids. On the other hand, heterochromatisation (or elimination) could occur during the first 


\section{Drosophilidae family Drosophila}

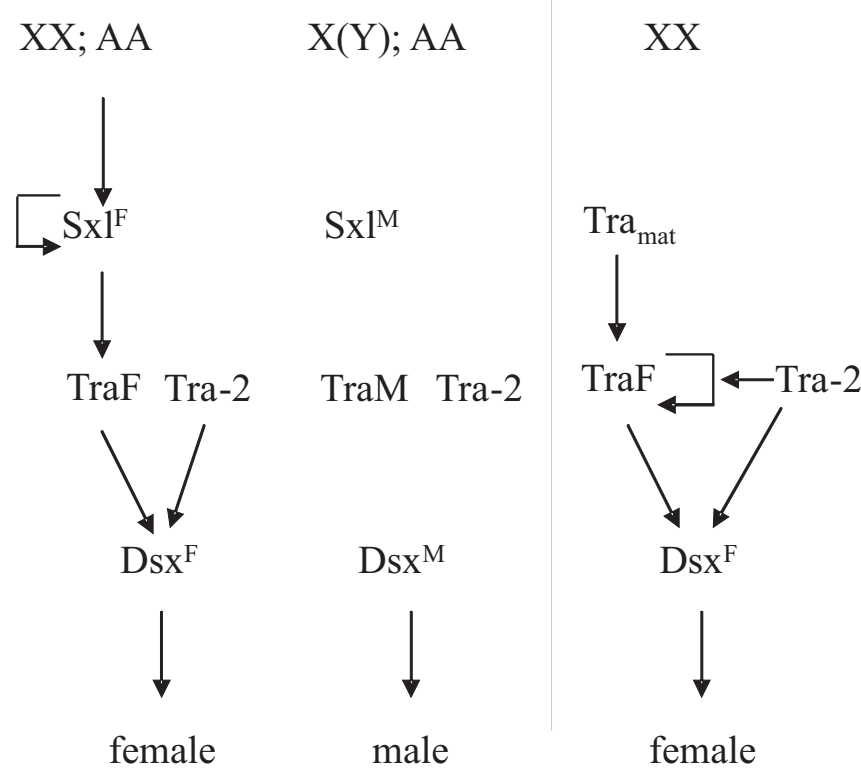

Tephritidae family

Ceratitis, Bactrocera, Anastrepha

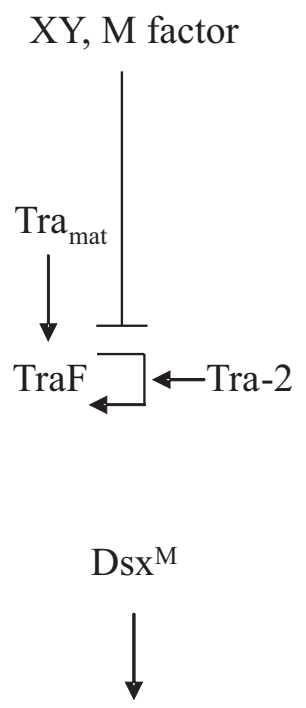

male

\author{
Muscidae family \\ Musca
}

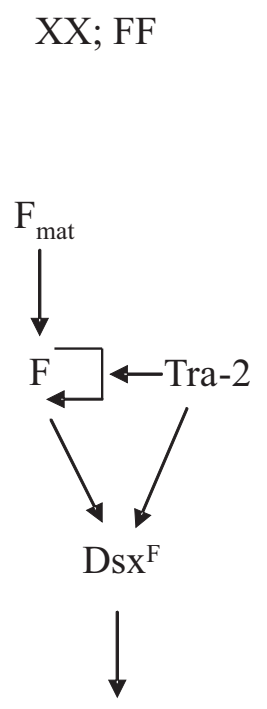

female

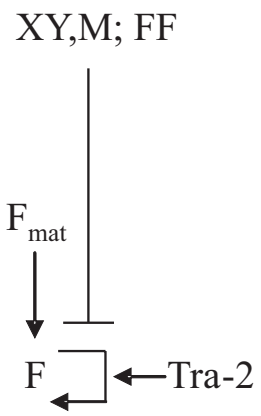

$\mathrm{Dsx}^{\mathrm{M}}$

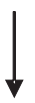

male

Fig. 9. The sex determination gene cascade in Drosophila, Ceratitis, Bactrocera, Anastrepha and Musca. Tra mat $_{\text {and }} F_{\text {mat }}$ indicate maternal Tra and F product respectively. The production of Dsx ${ }^{M}$ protein is the default state. The scheme for the Tephritidae is modified from Pane et al. (2002), and that for the Muscidae from Burghardt et al. (2005).

cleavage divisions, well before the first developmental (including sex determination) decisions have to be taken (at the blastoderm stage). Thus, heterochromatisation (or elimination) would precede sex determination and would depend on a maternal factor, whereas sex determination would depend on a zygotic chromosomal signal - haploidy or diploidy - which is transmitted after heterochromatisation occurs.

\section{The sex-determining genetic cascade: evolutionary aspects}

The characterisation in other insects of the genes homologous to those of the sex determination cascade in $D$. melanogaster (see above) allows the evolution of this genetic cascade to be analysed.

The Dsx proteins of different insects show a high degree of conservation, suggesting the presence of strong purifying selection acting on $d s x$ to preserve the mechanism of action of the Dsx proteins (Ruiz et al., 2007b). This further indicates the important function that $d s x$ has in controlling sexual development in insects.

The degree of conservation of Dsx proteins contrasts with the degree of variability of the Tra proteins. These show an unusually high degree of evolutionary divergence, yet the RS motifs (protein regions with many arginine-serine dipeptides) are conserved. The different degree of variability in the Dsx and the Tra proteins might be due to the less constrained structural requirements of Tra proteins with respect to the ability to perform their function. The RS domains appear to be the major functional part of the Tra protein, and the presence of just $10-20 \%$ of RS dipeptides in the Tra protein seems to be sufficient to bestow functionality (Kulathinal et al., 2003). Therefore, the Tra proteins probably underwent high rates of neutral evolution whenever they maintained the appropriate levels of RS dipeptides.

Comparison of the SxI proteins of dipteran species has shown their two RNA-binding domains (RBD) to be highly conserved, whereas the $\mathrm{N}$ - and $\mathrm{C}$-terminal domains show significant variation. The great majority of nucleotide changes in the RBDs appear to be synonymous, indicating that purifying selection is acting on them (Serna et al., 2004). These results support the contention that the main modifications that invest Drosophila SxI protein with its functional specificity are located in its terminal domains, outside the well-conserved RNA-binding domains (Meise et al., 1998; Saccone et al., 1998; Serna etal., 2004). For further studies on the phylogeny of $S x$ /see Traut et al. (2006b).

$S x /$ does not appear to play a key discriminatory role in the control of sex determination outside the drosophilids. In Ceratitis, this role appears to be played by the gene tra, whereas in the housefly Muscait is played by $F$. The model proposed for Ceratitis sex determination (Pane et al., 2002) and that for the housefly (Dübendorfer et al., 2002) show similarities (see Fig. 9).

The gene tra of Ceratitis, which plays a key regulatory role as the device memory for sex determination (via its autoregulation function) shows maternal expression (Pane et al., 2002). The latter authors proposed that tramRNA (or its protein) provided by the oocyte supplies the embryo with the Tra protein needed to impose female-specific splicing of the initial zygotic tra premRNA. This would produce the first zygotic functional Tra protein and consequently the establishment of tra autoregulation. In this scenario the $X X$ embryos follow female development. In $X Y$ embryos, however, the $M$ factor present in the $Y$ chromosome 
would prevent the setting up of the tra autoregulation system. Consequently, these embryos would not produce functional Tra protein and develop as males. The Bactrocera(Lagos et al., 2007) and Anastrepha (Ruiz et al., 2007a) tra genes show a similar molecular organisation and the same expression pattern (including their maternal expression) to those found in Ceratitis,. These results suggest that the tradevice memory mechanism, as well as the $\mathrm{M}$ factor mechanism for preventing the establishment of tra autoregulation, were likely present in the common ancestor of the Ceratitis, Bactrocera and Anastrepha phylogenetic lineages.

In the housefly, the gene $F$ plays the key role for female sex determination. It shows maternal expression and its maternal product is needed to activate the zygotic function of $F$, which appears to show autoregulation (Dübendorfer and Hediger, 1998). The gene tra-2is required for this autoregulation (Burghardt et al., 2005). In XY zygotes, the presence of the masculinising factor $M$ in the $\mathrm{Y}$ chromosome would prevent the establishment of $F$ autoregulation and cause male development (Dübendorfer et al., 2002).

Together, these results support the model of Wilkins (1995) who proposed that the evolution of the sex-determining cascades were built bottom up, with the genes at the bottom being more conserved than the more upstream genes in the cascade (for a theoretical analysis of this model see Pomiankowski et al., 2004). Indeed, the dsx-tra(or F)-tra2 elements at the bottom of the cascade, and their relationships, have been found conserved in all the dipterans so far analysed. This suggests they represent the ancestral state (which still exists in the Tephritidae and Muscidae

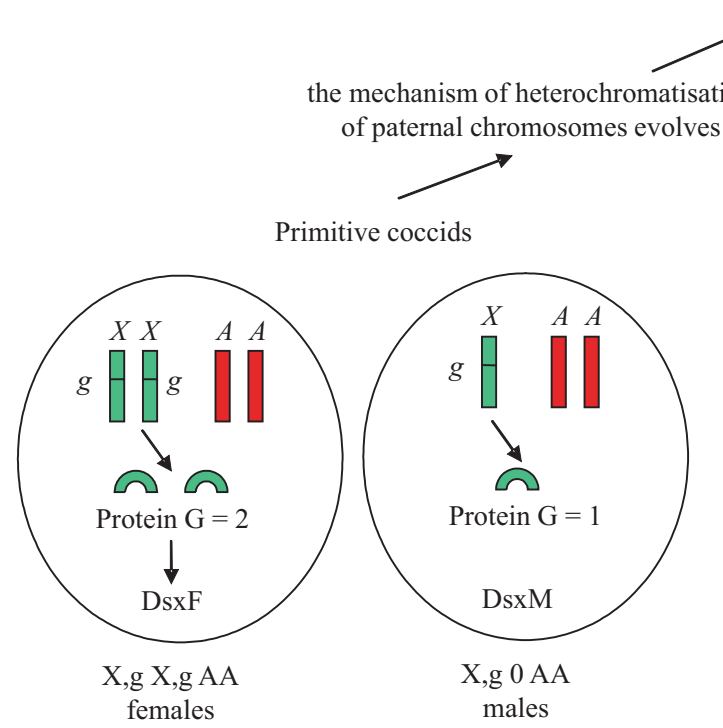

Fig. 10. The primary sex determination signal operative in both primitive and in lecanoid/diaspidid coccids. $X$ stands for the $X$ chromosome (green) and A for a set of autosomes (red) in the primitive coccids. Notice that in the lecanoid and diaspidid coccids Xm and Am stand for the maternally inherited chromosomes, and Xp and Ap for the paternally-inherited chromosomes. The green and red colours are maintained to indicate the origin of the chromosomes in the lecanoid/diaspidid coccids in relation to the primitive coccids. The black colour in the lecanoid mechanism symbolises the heterochromatic, genetically inert, chromosomal state. The production of Dsx ${ }^{M}$ protein is considered to be the default state. lineages) with respect to the extant cascade found in the more evolved Drosophilidae lineage, in which trais another component of the sex determination gene cascade regulated by $S x /$. Thus, in the phylogenetic lineage that gave rise to the drosophilids, evolution co-opted for the $S x / g e n e$, modified it, and converted it into the key gene controlling sex determination.

\section{Chromosome heterochromatisation or elimination and sex determination in coccids: evolutionary aspects}

In primitive coccids, gender is determined by the conventional $\mathrm{XX} / \mathrm{XO}$ system, and in more evolved coccids - lecanoids, comstockiellids and diaspidids - on a haploid/diploid system. It appears that the evolutionary sequence is lecanoid-comstockielliddiaspidid (Brown and McKenzie, 1962; for a theoretical analysis see Haig, 1933; Herrick and Seger, 1999 and references therein). There are two possible evolutionary scenarios for the primary sex determination signal in coccids. In one, the primary genetic signal that determines gender in both primitive and lecanoid/diaspidid coccids is the same. During the evolution of the lecanoid/diaspidid systems the only thing that changed was the appearance of a mechanism that brings about either diploidy or haploidy - whether structural or functional - of the embryo; the primary genetic signal

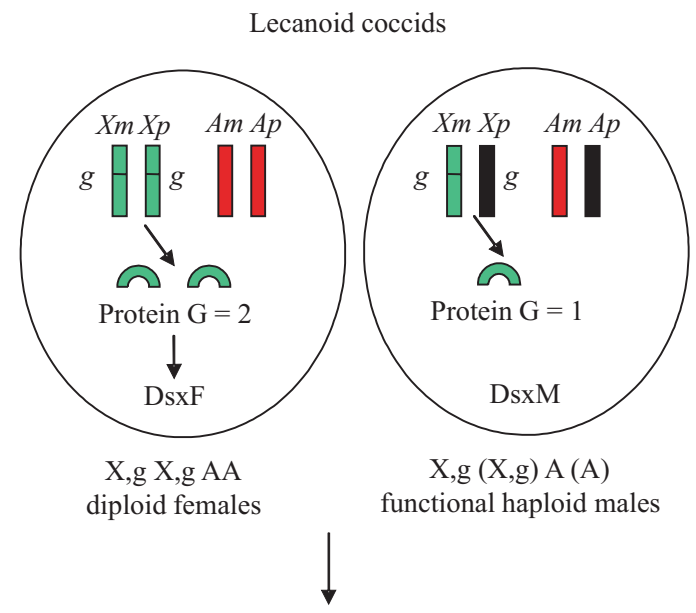

the mechanism of elimination of heterochromatic paternal chromosomes evolves
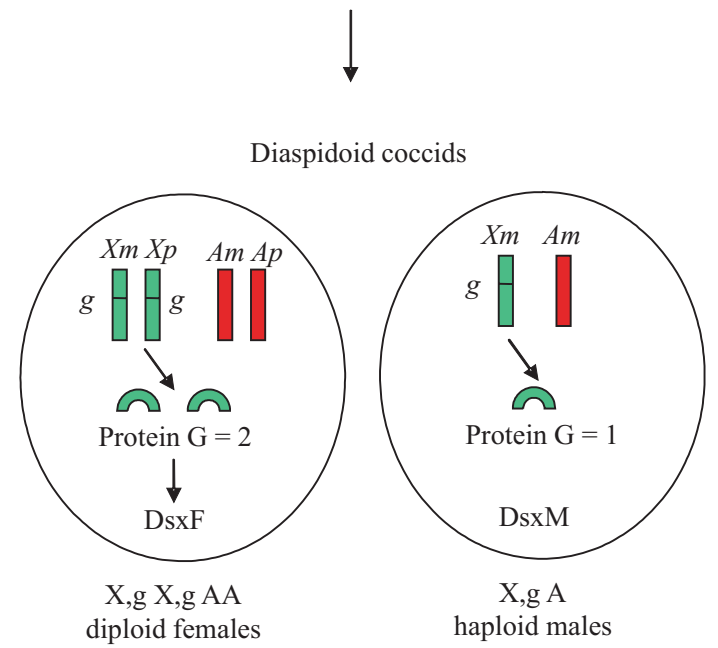
determining gender remained the same. In the second scenario, the sex-determining mechanism of primitive coccids could not operate with the haploid/diploid strategy evolved in the lecanoid/ diaspidid coccids, so a new primary genetic signal evolved. The question arises as to whether the putative primary genetic signal operating in primitive coccids is compatible with the haploid/ diploid mechanism operating in lecanoid/diaspidid coccids.

The $X X / X 0$ system of primitive coccids can be explained by four possible mechanisms depending on the primary signal determining the gender of the embryo.

1) In the first, the primary signal is formed by the ratio of $X$ chromosomes to sets of autosomes, with XXAA being females and XOAA males. This mechanism could not operate in the lecanoid/diaspidid coccids because both haploid (male) and diploid (female) embryos have the same female X/A signal. Consequently, only females would be produced.

2) In the second, the primary genetic signal results from a balance between female-determining factors located on the $X$ chromosome and male-determining factors with an autosomal location. This is the "genic balance system of sex determination" proposed by Bridges for Drosophila (Bridges, 1925). This hypothesis considers gender as a quantitative characteristic with continuous variation under the control of two opposing polygenic signals, whose component factors each have a small effect. The opposing action of these sets of signals would determine the gender of the embryo, according to the stechiometric assumption that two doses of the female-determining factor (2X chromosomes) outweigh the effect of two doses of the male-determining factor (2 sets of autosomes), leading to females being produced. However, two doses of male-determining factor (2 sets of autosomes) outweigh the effect of one dose of female-determining factor ( $1 \mathrm{X}$ chromosome), leading to male development. This mechanism could not operate in the lecanoid/diaspidid coccids since diploid (female) and haploid (male) embryos have the same ratio of female- and male-determining factors, thus only females could be produced.

3) In the third, the absolute number of $X$ chromosomes determines the primary genetic signal. In this scenario, $2 \mathrm{X}$ and $1 \mathrm{X}$ embryos will develop as females and males respectively, irrespective of the number of autosomal sets (see Fig. 10). From a genetic point of view, the simplest situation is when a single $X$ linked gene $(g)$ controls sex determination so that the amount of $G$ product dictates the sexual development of the zygote. Thus, $\mathrm{XX}$ (two doses of $g$ ) embryos will have twice the amount of $G$ product as XO (one dose of $g$ ) embryos. The former will follow the female pathway whereas the latter will follow the male pathway. This mechanism could operate in the primitive coccids and in the lecanoid and diaspidid coccids whenever two conditions are fulfilled. The first is that either gene $g$ is not subject to dosage compensation, or it exerts its function prior to the establishment of dosage compensation (if such a process exists). The second is that gene $g$ has only one functional allele. Let us assume that the sex-determining gene $g$ has two alleles: a functional and a nonfunctional allele, and that the presence of the functional allele determines female development and its absence causes male development. In this scenario, X0 embryos, or lecanoid/diaspidid haploid embryos, carrying the functional allele would develop as females, just like $X X$ embryos homozygous or heterozygous for the functional allele. On the other hand, XX embryos, or lecanoid/ diaspidid diploid embryos homozygous for the non-functional allele would develop as males.

4) In the fourth mechanism, the primary genetic signal is given by a complementary sex determiner (csd) locus, similar to the one found in the honeybee. This mechanism is a priori reconcilable with both primitive and lecanoid/diaspidid coccids whenever a high number of alleles exist in the population (see Fig. 4). In this scenario, allelic homozygosity, which causes diploid embryos to develop as males, would be infrequent. Notice that the csdlocus in the honeybee works in a haploid/diploid scenario. This is also the situation found in the lecanoid/diaspidid coccids. With respect to the primitive coccids, the $X$ chromosome is in the haploid condition in males, and in the diploid condition in females. However, the existence of some parthenogenic coccids known to produce female embryos (see above) makes this mechanism less plausible because these females are homoallelic for the putative csdlocus, and then they should develop as males instead of as females.

In conclusion, the only sex-determining mechanisms compatible with the $X X / X 0$ system of primitive coccids and the haploid/ diploid system of more evolved lecanoid/diaspidid coccids is that in which gender depends on the number of copies of an X-linked gene. However, certain conditions are necessary.

\section{Acknowledgements}

I am grateful to MF Ruiz, R Stefany, M Alvarez, I Martín and F. Sarno for their comments on the manuscript. This work was financed by grants BFU2005-03000 awarded to L. Sánchez by the D.G.I.C.Y.T., Ministerio de Educación y Ciencia, España.

\section{References}

ALBRECHT, E.B. and SALZ, H.K. (1993). The Drosophila sex determination gene snfis utilized for the establishment of the female-specific splicing pattern of Sexlethal. Genetics 134: 801-807.

ARTHUR, B.I., JALLON, J.M., CAFLISCH, B., CHOFFAT, Y. and NÖTHIGER R (1998) Sexual behaviour in Drosophila is irreversibly programmed during a critical period. Current Biology 8: 1187-1190.

BACHILLER, D. and SÁNCHEZ, L. (1991). Production of XO clones in XX females of Drosophila. Genet. Res. 57: 23-28.

BAKER, B. and RIDGE, K. (1980). Sex and the single cell. I. On the action of the major loci affecting sex determination in Drosophila melanogaster. Genetics 94 : 383-423.

BELL, L.R., MAINE, E.M., SCHEDL, P. and CLINE, T.W. (1988). Sex-lethal, a Drosophila sex determination switch gene, exhibits sex-specific RNA splicing and sequence similar to RNA binding proteins. Cel/55: 1037-1046.

BELL, L.R., HORABIN, J.I., SCHEDL, P. and CLINE, T.W. (1991). Positive autoregulation of Sex-letha/by alternative splicing maintains the female determined state in Drosophila. Cel/65: 229-239.

BELOTE, J.M., McKEOWN, M., BOGGS, R.T., OHKAWA, R., and SOSNOWSKI, B.A. (1989). The molecular genetics of transformer, a genetic switch-controlling sexual differentiation in Drosophila. Devel. Genet. 10: 143-154.

BERRY, R.O. (1941). Chromosome beahvior in the germ cells and development of the gonads in Sciara ocellaris. J.Morphol. 68: 547-583.

BEUKEBOOM, L.W., KAMPING, A. and DE ZANDE, L. (2007). Sex determination in the haplodiploid wasp Nasonia vitripennis (Hymenoptera: Chalcidoidea): A critical consideration of models and evidence. Seminars in Cell and Developmental Biology 18: 371-378.

BEYE, M., HASSELMANN, M., KIM FONDRK, M., PAGE, R.E.Jr. and OMHOLT, S.S. (2003). The gene $c s d$ is the primary signal for sexual development in the honeybee and encodes an SR-type protein. Cel/114: 419-429.

BEYE, M. (2004) The dice of fate: the csd gene and how its allelic composition 
regulates sexual development in the honeybee, Apis mellifera. Bioessays 26: 1131-1139.

BILLETER, J.C., GOODWIN, S. and O'DELL, K.M.C. (2002). Genes mediating sexspecific behaviors in Drosophila. Adv. Genet. 47: 87-150.

BILLETER, J.C., RIDEOUT, E.J., DORNAN, A.J. and GOODWIN, S.F. (2006). Control of male behavior in Drosophila by the sex determination pathway. Current Biology 16: R766-R776.

BOGGS, R.T., GREGOR, P., IDRISS, S., BELOTE, J.M. and MCKEOWN, M. (1987). Regulation of sexual differntiation in Drosophila melanogaster via alternative splicing of RNA from the transformer gene. Cel/50: 739-747.

BOPP, D., BELL, L.R., CLINE, T.W. and SCHEDL, P. (1991). Developmental distribution of female-specific Sex-lethal proteins in Drosophila melanogaster. Genes Devel. 5: 403-415.

BOPP, D., CALHOUN, G., HORABIN, J.I., SAMUELS, M. and SCHEDL, P. (1996). Sex-specific control of Sex-letha/is a conserved mechanism for sex determination in the genus Drosophila. Development 122: 971-982.

BOTELLA, L.M., DOÑORO, C., SÁNCHEZ, L., SEGARRA, C. and GRANADINO, B. (1996). Cloning and characterization of the scute (sc) gene of Drosophila subobscura. Genetics 144: 1043-1051.

BRIDGES, C.B. (1925). Sex in relation to chromosomes and genes. Am. Nat. 59: 127-137.

BROWN, S.W. and BENNETT, F.D. (1957). Opn sex determination in the diaspine scale Pseudaulacaspis pentagona (Targ.) (Coccoidea). Genetics 42: 510-523.

BROWN, SW. and NELSON-REES, W.A. (1961). Radiation analysis of a lecanoid genetic system. Genetics 46: 983-1007.

BROWN, S.W. and McKENZIE, H.L. (1962). Evolutionary patterns in the armoured scale insects and their allies. Hilgardia 33: 141-170.

BROWN, S.W. and NUR, U. (1964). Heterochromatic chromosomes in the coccids. Science 145: 130-136.

BROWN, S.P. (1977). Adaptive status and genetic regulation in major evolutionary changes of coccid chromosome systems. Nucleus 20: 145-157.

BROWN, SW. and CHANDRA, H.S. (1977). Chromosome imprinting and the differential regulation of homologous chromosomes. In Cell Biology:A comparative treatise, volume 1, Genetic mechanisms of cells, ed. Goldstein, L. and Prescott, D.M., pp. 108-189. New York, Academic.

BULL, J.B. (1983). Evolution of sex determining mechanisms. The Benjamin/ Cummings Publishing Company, Inc, Menlo Park, California, USA.

BURGHARDT, G., HEDIGER, M., SiEgenthAlER, C., MOSER, M., DÜBENDORFER, A. and BOPP, D. (2005). The transfromer2 gene in Musca domestica is required for selecting and maintaining the female pathway of development. Dev. Genes Evol. 215: 165-176.

BURTIS, K.C. and BAKER, B.S. (1989). Drosophila doublesex gene controls somatic sexual differentiation by producing alternatively spliced mRNAs encoding related sex-specific polypeptides. Cel/56: 997-1010.

CAMPOS, M.C., NIGRO, R.G. and PERONDINI, A.L.P. (1996). Evidencia de imprinting genomico em um loco genico do diptero Sciara ocellaris. Brazil. J. Genet. 19: (suppl.): 186.

CHANDLER, D., MCGUFFIN, M., PISKUR, J., YAO, J., BAKER, B. and MATTOX, W. (1997). Evolutionary conservation of regulatory strategies for the sex determination factor transformer-2. Mol. Cell Biol. 17: 2908-2919.

CHANDRA, H.S. (1962). Inverse meiosis in triploid females of the mealy bug, Planococcus citri. Genetics 46: 983-1007.

CHANDRA, H.S. (1963). Cytogenetic studies following high dosage paternal irradiation in the mealy bug, Planococcus citri. Chromosoma 14: 330-346.

CHASE, B.A. and BAKER, B.S. (1995). A genetic analysis of intersex, a gene regulating sexual differentiation in Drosophila melanogasterfemales. Genetics 139: 1649-1661.

CLINE, T.W. (1978). Two closely-linked mutations in Drosophila melanogasterthat are lethal to opposite sexes and interact with daughterless. Genetics 90: 683698.

CLINE, T.W. (1984). Autoregulatory functioning of a Drosophila gene product that establishes and maintains the sexually determined state. Genetics 107: 231277.

CLINE, T. W., (1993). The Drosophila sex determination signal: how do flies count to two? Trends Genet. 9: 385-390.
CLINE, T.W. and MEYER, B.J. (1996). Vive la différence: males vs. females in flies vs. worms. Annu. Rev. Genet. 30: 637-702.

CLINE, T.W., RUDNER, D.Z., BARBASH, D.A., BELL, M. and VUTIEN, R. (1999). Functioning of the Drosophilaintegral U1/U2 protein Snf independent of U1 and U2 small nuclear ribonucleoprotein particles is revealed by snf gene dose effects. Proc. Natl. Acad. Sci. USA 96: 14451-14458.

COOK, J.J. (1993). Sex determination in the hymenoptera: a review of models and evidence. Heredity 71: 421-435.

CROUSE, H.V. (1960). The nature of the influence of X-translocations on sex of progeny in Sciara coprophila. Chromosoma 11: 146-166.

DAVIDHEISER, B. (1943). Inheritance of the X chromosome in exceptional males of Sciara ocellaris (Diptera). Genetics 28: 193-199.

DE LOOF, A. AND HUYBRECHTS, R. (1998). "Insects do not have sex hormones": A myth? General and Comparative Endocrinology 111: 245-260.

DE SAINT-PHALLE, B. and SULLIVAN, W. (1996). Incomplete sister chromatid separation is the mechanism of programmed chromosome elimination during early Sciara coprophila embryogenesis. Development 122: 3775-3784.

DUBOIS, A. (1932). A contribution to the morphology of Sciara. J. Morph. 43: 5084.

DÜBENDORFER, A. and HEDIGER, M. (1998). The female-determining gene F of the housefly, Musca domestica, acts maternally to regulate its own zygotic activity. Genetics 150: 221-226.

DÜBENDORFER, A., HEDIGER, M., BURGHARDT, G. and BOPP, D. (2002). Musca domestica, a window on the evolution of sex-determining mechanisms in insects. Int. J. Dev. Biol. 46: 75-79.

DUBOIS, A.M. (1933). Chromosome behaviour during cleavage in the eggs of Sciara coprophila (diptera) in relation to the problem of sex determination. $Z$. Zellforsch. Mikrosk. Anat. 19: 595-614.

ERICKSON, J.W. and CLINE, T.W. (1998). Key aspects of the primary sex determination mechanism are conserved across the genus Drosophila. Development 125: 3259-3268.

ERICKSON, J.W. and QUINTERO, J.J. (2007). Indirect effects of ploidy suggest X chromosome dose, not the X:A ratio, signals sex in Drosophila. PloS Biology 5(11): e332.doi:10.1371/journal.pbio.0050332.

ESTEBAN, R., CAMPOS, C.C., PERONDINI, A.L.P. and GODAY, C. (1997). Role of microtubules and microtubule organizing centers on meiotic chromosome elimination in Sciara ocellaris. J. Cell Sci. 9: 610-629.

EZAZ, T., STIGLEC, R., VEYRUNES, F. and MARSHALL GRAVES, J. A. (2006). Relationships between vertebrate $Z W$ and $X Y$ sex chromosome systems. Current Biology 16: R736-R743.

FLICKINGER, T.W. and SALZ, H.K. (1994). The Drosophila sex determination gene snfencodes a nuclear protein with sequences and functional similarity to the mammalian U1A snRNP protein. Genes Devel. 8: 914-925.

FUGE, H. (1994). Unorthodox male meiosis in Trichosia pubescens (Sciaridae). Chromosome elimination involves polar organelles degeneration and monocentric spindlesin 1rst and second división. J. Cell Sci. 96: 188-201.

GAILEY, D.A., BILLETER, J.C., LIU, J.H., BAUZON, F., ALLENDORFER, J.B. and GOODWIN, S.F. (2006). Functional conservation of the fruitless male sexdetermination gene across 250 Myr of insect evolution. Mol. Biol. Evol. 23: 633643.

GARRETT-ENGELE, C.M., SIEGAL, M.L., MANOLI, D.S., WILLIAMS, B.C., LI, H. and BAKER, B.S. (2002). intersex, a gene required for female sexual development in Drosophila, is expressed in both sexe4s and functions together with doublesex to regulate terminal differentiation. Development 129: 4661-4675.

GERBI, S.A. (1986). Unusual chromosome movements in sciarid flies. In: Hennig, W. (Ed.), Germ Line-Soma Differentiation. Springer-Verlag, Berlin, pp. 71-104.

GODAY, C. and ESTEBAN, R. (2001). Chromosome elimination in sciarid flies. Bioessays 23: 242-250.

GOODWIN, S.F., TAYLOR, B.J-, VILLELA, A., FOSS, M., RYNER, L.C., BAKER, B.S. and HALL, J.C. (2000). Molecular defects in the expression of the fruitless gene of Drosophila melanogaster caused by aberrant splicing in P-element insertional mutants. Genetics 154: 725-745.

GRANADINO, B., CAMPUZANO, S. and SÁNCHEZ, L. (1990). The Drosophila melanogasterfl(2)dgene is needed for the female-specific splicing of Sex-lethal RNA. EMBO J. 9: 2597-2602. 
GRANADINO, B., PENALVA, L.O.F. and SÁNCHEZ, L. (1996). The gene fl(2)dis needed for the sex-specific splicing of transformerpre-mRNA but not for doublesexpremRNA in Drosophila melanogaster. Mol. Gen. Genet. 253: 26-31.

GREENSPAN, R.J. and FERVEUR, J.F. (2000). Courtship in Drosophila. Annu. Rev. Genet. 34: 205-232.

GUATIMOSIN, V.M.B. and PERONDINI, A.L.P. (1994). Lethal effects of far UV on preblastoderm embryos of Sciara ocellaris(Diptera, Sciaridae). BrazilJ. Genet. 17: $25-34$.

GUATIMOSIN, V.M.B. (1996). Efeitos da radiaçao ultavioleta no processao de eliminaçao do cromossomos $X$ nos núcleos somáticuos de diptero Sciara ocellaris (Diptera: Sciaridae). PhD. Thesis. Departamento de Biología, Instituto de Biociencias, Universidade de Sao Paulo, Sao Paulo, Brazil.

HAIG, D. (1993). The evolution of unusual chromosome systems in coccids: extraordinary sex ratios revisited. J. Evol. Biol. 6: 69-77.

HEDIGER, M., BURGHARDT, G., SIEGENTHALER, C., BUSER, N., HILFIKERKLEINER, D., DÜBENDORFER, A. and BOPP, D. (2004). Sex determination in Drosophila melanogaster and Musca domestica converges at the level of the terminal regulator doublesex. Dev Genes Evol. 214: 29-42.

HEDLEY, M. and MANIATIS, T. (1991). Sex-specific splicing and polyadenylation of $d s x$ pre-mRNA requires a sequence that binds specifically to tra- 2 protein in vitro. Cel/65: 579-586.

HEINRICHS, V., RYNER, L.C., BAKER, B.S. (1998) Regulation of sex-specific selection of fruitless 5' splice sites by transformerand transformer-2. Mol. Cell. Biol. 18:450-458.

HERRICK, G. and SEGER, J. (1999). Imprinting and paternal genome elimination in insects. Results probl. Cell Diff. 25: 41-71.

HERTEL, K.J., LYNCH, K.W., HSIAO, E.C., LIU, E.H.T. and MANIATIS, T. (1996). Structural and functional conserevation of the Drosophila doublesex splicing enhancer reèat elements. RNA 2: 969-981.

HILFIKER, A. and NÖTHIGER, R. (1991). The temperature-sensitive mutation vir (virilizer) identifies a new gene involved in sex determination of Drosophila. Roux's Arch. Devel. Biol. 200: 240-248.

HILFIKER, A., AMREIN, H., DÜ BENDORFER, A., NÖTHIGER, R., (1995). The gene virilizeris required for female-specific splicing controlled by $S x$, the master gene for sexual development in Drosophila. Development 121: 4017-4026.

HORABIN, J.I. and SCHEDL, P. (1996). Splicing of the Drosophila Sex-letha/early transcripts involves exon skipping that is independent of Sex-lethal protein. RNA 2: 1-10.

HOSHIJIMA, K., INOUE, K., HIGUCHI, I., SAKAMOTO, H. and SHIMURA, Y. (1991). Control of doublesex alternative splicing by transformer and transformer-2 in Drosophila. Science 252: 833-836.

JAMES, H.C. (1937). Sex ratios and the status of the male in Pseudococcinae (hem. Coccidae). Bull. Ent. Res. 28: 429-461.

JAMES, H.C. (1938). The effect of the humidity of the environment on sex ratios from over-aged ova of Peudococcus citri(Risso). Roy. Ent. Soc. London, Proc. Ser. A Gen. Ent. 13: 73-79.

KELLEY, R.L., WANG, J., BELL, L. and KURODA, M.I. (1997) Sex letha/controls dosage compensation in Drosophila by a non-splicing mechanism. Nature 387: 195-199.

KEYES, L.N., CLINE, T.W. and SCHEDL, P. (1992). The primary sex determination signal of Drosophila acts at the level of transcription. Cel/68: 933-943.

KUHN, S., SIEVERT, V. and TRAUT, W. (2000). The sex-determining gene doublesex in the fly Megaselia scalaris. conserved structure and sex-specific splicing. Genome 43: 1011-1020.

KULATHINAL, R.J., SKWAREK, L., MORTON, R.A. and SINGH, R.S. (2003). Rapid evolution of the sex-determining gene, transformer. structural diversity and rate heterogeneity among sibling species of Drosophila. Mol. Biol. Evol. 20: 441-452.

LAGOS, D., RUIZ, M.F., SÁNCHEZ, L. and KOMITOPOULOU, K. (2005). Isolation and characterization of the Bactrocera oleae genes orthologous to the sex determining Sex-lethal and doublesex genes of Drosophila melanogaster. Gene 384: 111-121.

LAGOS, D., KOUKIDOU, M., SAVAKIS, C. and KOMITOPOULOU, K. (2007). The transformergene in Bactrocera oleae. the genetic switch that determines its sex fate. Insect Mol. Biol. 16: 221-230.
LALLI, E., OHE, K., LATORRE, E., BIANCHI, M.E., SASSONE-CORSI, P. (2003). Sexy splicing: regulatory interplays governiong sex determination from Drosophila to mammals. J. Cell Sci. 116: 441-445.

LI, H. and BAKER, B.S. (1998). hermaphrodite and doublesex function both dependently and independently to control various aspects of sexual differentiation in Drosophila. Development 125: 2641-2651.

LIU, P.Y. (1968). Estudo biologico de cultura de Bradysi tritici(Diptera, Sciaridae) parasitada por gregarina. Master Dissertation. Departamento de Biología, Instituto de Biociencias, Universidade de Sao Paulo, Sao Paulo, Brazil.

LOUIS, M., HOLM, L., SÁNCHEZ, L. and KAUFMAN, M. (2003). A theoretical model for the regulation of Sex-letha, a gene that controls sex determination and dosage compensation in Drosophila melanogaster. Genetics 165: 1355-1384.

MACDOUGALL, C., HARBINSON, D. AND BOWNES M. (1995). The developmental consequences of alternate splcing in sex determination and differentiation in Drosophila. Dev. Biol. 172: 353-376.

MANOLAKOU, P., LAVRANOS, G. AND ANGELOPOULOU, R. (2006). Molecular patterns of sex determination in the animal kingdom: a comparative study of the biology of reproduction. Reproductive Biology and Endocrinology 4: 59. doi:10.1186/1477-7827-59.

MEISE, M., HILFIKER-KLEINER, D., DÜBENDORFER, A., BRUNNER, C., NÖTHIGER, R. and BOPP, D. (1998). Sex-lethal, the master sex-determining gene in Drosophila, is not sex-specifically regulated in Musca domestica. Development 125: 1487-1494.

METZ, C.W. and SCHMUCK, M.L. (1929). Unisexual progenies and the sex chromosomes mechanism in Sciara. Proc. Natl. Acad. USA. 15: 863-866.

METZ, C.W. (1938). Chromosome behavior, inheritance and sex determination in Sciara. Amer. Nat. 72: 485-520.

MILLER, D.R. and KOSZTARAB, M. (1979). Recent advances in the study of scale insects. Ann. Rev. Entomol. 24: 1-27.

MORI, L., DESSEN, E.M. and PERONDINI, A.L.P. (1979). A gedne that modifies the sex ratio in a bisexual strain of Sciara ocellaris. Heredity 42. 353-357.

MOSES, M.S. and METZ, C.W. (1928). Evidence that the female is responsible for the sex ratio in Sciara (Diptera). Proc. Natl. Acad. Sci. USA. 14: 928-930.

MÜLLER-HOLTKAM, F. (1995). The Sex-lethal gene in Chrysomya rufifacies is highly conserved in sequence and exon-intron organization. J. Mol. Evol. 41, 467-477.

NELSON-REES, W.A. (1960). A stydy of sex predetermination in the mealy bug Planococcus citri (risso). J. Exp. Zool. 144: 111-137.

NIESSEN, M., SCHNEITER, R. and NÖTHIGER, R. (2001). Molecular identification of virilizer, a gene required for the expression of the sex-determining gene Sexletha/in Drosophila melanogaster. Genetics 157: 679-688.

NIIMI, T., SAHARA, K., OSHIMA, H., YASUKOCHI, Y., IKEO, K. and TRAUT, W. (2006a). Molecular cloning and chromosomal localization of the Bombyx Sexletha/gene. Genome 49: 263-268.

NIGRO, R.G. (1995). Efeito da temperatura na determinaçao sexual de Sciara ocellaris (Diptera: Sciaridae).

NIGRO, R.G., CAMPOS, C.C. and PERONDINI, A.L.P. (2007). Temperature and the progeny sex-ratio in Sciara ocellaris (Diptera, Sciaridae). Genetics and Molecular Biology 30: 152-158.

NUR, U. (1990). Heterochromatization and euchromatization of whole genomes in scale insects (Coccoidea: Homoptera). Development Suppl. 1990: 29-34.

NUR, U. (1962). A supernumerary chromosome with an accumulation mechanism in the lecanoid genetic system. Chromosoma 13: 249-271.

NUR, U. (1963). Meiotic parthenogenesis and heterochromatization in a soft scale, Pulvinaria hydrangeae (Coccoidea: Homoptera). Chromosoma 14: 123-139.

OHBAYASHI, F., SUZUKI, M., MITA, K., OKANO, K. and SHIMADA, T. (2001). A homologue of the Drosophila doublesex gene is transcribed into sex-specific mRNA isoforms in the silkworm, Bombyx mori. Comp. Biochem. Physiol. 128: 145-158.

O'KANE, C. and ASZTALOS, Z. (1999). Sexual behaviour: courting dissatisfaction. Current Biol. 9: R289-R292.

OLIVER, B. (2002). Genetic control of germline sexual dimorphism in Drosophila. Int. Rev. Cytol. 219: 1-60.

O'NEIL, M.T. and BELOTE, J.M. (1992). Interspecific comparison of transformer 
gene of Drosophila reveals an unusually high degree of evolutionary divergence. Genetics 131: 113-128.

ORTEGA, A., NIKSIC, M., BACHI, A., WILM, M., SÁNCHEZ, L., HASTIE, N. and VALCÁRCEL, J. (2003). Biochemical function of female-lethal (2)d/Wilms' tumor suppressor-1- associated proteins in alternative pre-mRNA splicing. J. Biol. Chem. 278: 3040-3047.

PANE, A., SALVEMINI, M., BOVI, P.D., POLITO, C. and SACCONE, G. (2002). The transformer gene in Ceratitis capitata provides a genetic basis for selecting and remembering the sexual fate. Development 129: 3715-3725.

PANE, A., DE SIMONE, A., SACCONE, G and POLITO, C. (2005). Evolutionary conservation of Ceratitis capitata transformergene function. Genetics 171: 615624.

PENALVA, L.O.F., SAKAMOTO, H., NAVARRO-SABATE, A., SAKASHITA, E., GRANADINO, B., SEGARRA, C. and SÁNCHEZ, L. (1996). Regulation of the gene Sex-lethat. a comparative analysis of Drosophila melanogaster and Drosophila subobscura. Genetics 144: 1653-1664.

PENALVA, L.O.F., RUIZ, M.F., ORTEGA, A., GRANADINO, B., VICENTE, L., SEGARRA, C., VALCÁRCEL, J. and SÁNCHEZ, L. (2000). The Drosophila $f(2) d$ gene, required for female-specific splicing of $S x /$ and tra pre-mRNAs, encodes a novel nuclear protein with a HQ-rich domain. Genetics 155: 129-139.

PENALVA, L.O.F. and SÁNCHEZ, L. (2003). The RNA binding protein Sex-lethal (Sxl) and the control of Drosophila sex determination and dosage compensation. Microbiology and Molecular Biology Reviews 67: 343-359.

PERONDINI. A.L.P., GUTZEIT, H.O. and MORI, L. (1986). Nuclear division and migration during early embryogenesis of bradysia tritici Coquillet (syn. Sciara ocellaris) (diptera: Sciaridae). Int. J. Insect Morphol. Embryol. 15: 155-163.

PERONDINI, A.L.P., GUTZEIT, H.O. and SANDER, K. (1987). Double abdomen induction by UV in Bradysia tritici (sy. Sciara ocellaris, Sciaridae): sensitive stages and conditions for photoreversal. Roux's Arch. Dev. Biol. 196: 268-272.

PERONDINI, A.L.P. and RIBEIRO, A.F. (1997). Chromosome elimination in germ cells of Sciara embryos: involvement of the nuclear envelope. Invert. Reprod. Development. 21: 20-30.

PERONDINI, A.L.P. (1998). Elimination of X chromosomes. In: Chatterjee, R., Sánchez, L. (Eds.), Genome Analysis in Eukaryotes: Developmental and Evolutionary Aspects. Narosa Publishing House (Springer-Verlag), India, pp. 38-55.

POMIANKOWSKI, A., NÖTHIGER, R. AND WILKINS, A. (2004). The evolution of the Drosophila sex-determination pathway. Genetics 166: 1761-1773.

PULTZ, M. and BAKER, B. (1995). The dual role of hermaphroditein the Drosophila sex determination regulatory hierarchy. Development 121: 99-111.

RIDEOUT, E.J., BILLETER, J.C. and GOODWIN, S.F. (2007). The sex-determination gene fruitless and doublesex specify a neural substrate required for courtship song. Current Biology 17: 1473-1478.

RIEFFEL, S. and CROUSE, H. (1966). The elimination and differentiation of chromosomes in the germ line of Sciara. Chromosoma 8: 120-165.

RUIZ, M.F., GODAY, C., GONZÁLEZ, P. and SÁNCHEZ, L. (2003). Molecular analysis and developmental expression of the Sex-lethal gene of Sciara ocellaris(Diptera Order, Nematocera Suborder). Gene Expr. Patt. (Mech. Dev.) 3: 341-346.

RUIZ, M.F., STEFANI, R.N., MASCARENHAS, R.O., PERONDINI, A.L.P., SELIVON, D. and SÁNCHEZ, L. (2005). The gene doublesex of the fruit fly Anastrepha obliqua (Diptera, Tephritidae). Genetics 171: 849-854.

RUIZ, M.F., MILANO, A., SALVEMINI, M., EIRÍN-LÓPEZ, J.M., PERONDINI, A.L.P., SELIVON, D., POLITO, C., SACCONE, G. and SÁNCHEZ, L. (2007a). The gene transformer of Anastrepha fruit flies (Diptera, Tephritidae) and its evolution in insects. PLoS ONE2(11):e1239.doi:10.1371/journal.pone.0001239.

RUIZ, M.F., EIRÍN-LÓPEZ, J.M., STEFANI, R.N., PERONDINI, A.L.P., SELIVON, D. and SÁNCHEZ, L. (2007b). The gene doublesex of Anastrepha fruit flies (Diptera, Tephritidae) and its evolution in insects. Dev. Genes Evol. 217: 725731.

RYNER, L.C. and BAKER, B.S. (1991). Regulation of doublesex pre-mRNA processing occurs by 3'-splice site activation. Genes Dev. 5: 2071-2085.

RYNER, L.C., GOODWIN, S.F., CASTRILLON, D.H., ANAND, A., VILLELA, A., BAKER, B.S., HALL, J.C., TAYLOR, B.J. and WASSERMAN, S.A. (1996) Control of male sexual orientation in Drosophila by the fruitless gene. Cel/87: 1079-1089.
SACCONE, G., PELUSO, I., ARTIACO, D., GIORDANO, E., BOPP, D. and POLITO, L.C. (1998). The Ceratitis capitata homologue of the Drosophila sexdetermining gene Sex-letha/is structurally conserved, but not sex-specifically regulated. Development 125: 1495-1500.

SALZ, H.K. and FLICKINGER, T.W. (1996). Both loss-of-function and gain-offunction mutations in snf define a role for snRNP proteins in regulating Sexletha/pre-mRNA splicing in Drosophila development. Genetics 144: 95-108.

SALZ, H.K., MAINE, E.M., KEYES, L.N., SAMUELS, M.E., CLINE, T.W. and SCHEDL, P. (1989). The Drosophila femalespecific sex-determination gene, Sex-lethal, has stage-, tissue-, and sex-specific RNAs suggesting multiple modes of regulation. Genes Devel. 3: 708-719.

SAMUELS, M.E., BOPP, D., COLVIN, R.A., COSCIGNO, R.F., GARCIA-BLANCO, M.A. and SCHEDL, P. (1994) RNA binding by Sxl proteins in vitro and in vivo. Mol. Cell. Biol. 14: 4975-4990.

SAMUELS, M.E., DESHPANDE, G. and SCHEDL, P. (1998). Activities of the Sexlethal protein in RNA binding and protein: protein interactions. Nucl. Acids Res. 26: 2625-2637.

SÁNCHEZ, L. and NÖTHIGER, R. (1983). Sex determination and dosage compensation in Drosophila melanogaster. production of male clones in XX females. EMBO J. 2: 485-491.

SÁNCHEZ, L., GRANADINO, B. and TORRES, M. (1994). Sex determination in Drosophila melanogaster. X-linked genes involved in the initial step of Sexletha/activation. Devel. Genet. 15: 251-264.

SÁNCHEZ, L., LÓPEZ, P. and GRANADINO, B. (1998). Early events associated with sex determination in Drosophila melanogaster. In: Chatterjee, R., Sánchez, L. (Eds.), Genome Analysis in Eukaryotes: Developmental and Evolutionary Aspects. Narosa Publishing House (Springer-Verlag), India, pp. 98-119.

SÁNCHEZ, L. and PERONDINI, A.L.P. (1999). Sex determination in sciarid flies: a model for the control of differential X-chromosome elimination. J. Theor. Biol. 197: 247-259.

SÁNCHEZ, L. and NÖTHIGER, R. (1983). Sex determination and dosage compensation in Drosophila melanogaster. production of male clones in XX females. EMBO J. 2: 485-491.

SÁNCHEZ, L., GORFINKIEL, N. and GUERRERO, I. (2005). Sex determination and the development of the genital disc. In Comprehensive Molecular Insect Science, Vol. 1, GILBERT, L.I., IATROU, K. and GILL, S.S. (eds.), ElsevierPergamonOxford, UK, pp. 1-38.

SCALI, C., CATTERUCCIA, F., LI, Q. and CRISANTI, A. (2005). Identification of sexspecific transcripts of the Anopheles gambiae doublesex gene. J. Exp. Biol. 208: 3701-3709.

SCHÜTT, C. and NÖTHIGER, R. (2000). Structure, function and evolution of sexdetermining system in Dipteran insects. Development 127: 667-677.

SERNA, E., GORAB, E., RUIZ, M.F., GODAY, C., EIRÍN-LÓPEZ, J.M. and SÁNCHEZ, L. (2004). The gene Sex-letha/ of the Sciaridae family (Order Diptera, Suborder Nematocera) and its phylogeny in dipteran insects. Genetics 168: 907-921.

SHEARMAN, D. and FROMMER, M. (1998). The Bactrocera tryonihomologue of the Drosophila melanogastersex determination gene doublesex. Insect Mol. Biol. 7: 355-366.

SHIRANGI, T.R., TAYLOR, B.J. and MCKEOWN, M. (2006). A double-switch system regulates male courtship behavior in male and female Drosophila melanogaster. Nature Genetics 38: 1435-1439.

SIEGAL, M.L. and BAKER, B.S. (2005). Functional conservation and divergence of intersex, a gene required for female differentiation in Drosophila melanogaster. Dev. Genes Evol. 215: 1-12.

SIEVERT, V., KUHN, S. and TRAUT, W. (1997). Expression of the sex determination cascade genes Sex-lethal and doublesex in the phorid fly Megaselia scalaris. Genome 40, 211-214.

SIEVERT, V., KUHN, S., PAULULAT, A. and TRAUT, W. (2000). Sequence conservation and expression of the Sex-letha/homologue in the fly Megaselia scalaris. Genome 43: 382-390.

STUART, J.J. and HATCHETT, J.H. (1991). Genetics of sex determination in the Hessian fly, Mayetiola destructor. J. Heredity 82. 43-52.

SUZUKI, M.G., OHBAYASHI, F., MITA, K. and SHIMADA, T. (2001). The mechanism of sex-specific splicing at the doublesex gene is different between Drosophila melanogasterand Bombyx mori. Insect Biochem. Mol. Biol. 31: 1201-1211.

TIAN, M. and MANIATIS, T. (1993). A splicing enhancer complex controls alterna- 
tive splicing of doublesex pre-mRNA. Cel/74: 105-114.

TORRES, M. and SÁNCHEZ, L. (1991). The sisterless-bfunction of the Drosophila gene scute is restricted to the state when the $\mathrm{X}: \mathrm{A}$ ratio signal determines the activity of Sex-lethal. Development 113: 715-722.

TRAUT, W., NIIMI, T., IKEO, K. and SAHARA, K. (2006). Rhylogeny of the sexdetermining gene Sex-letha/in insects. Genome 49: 254-262.

VALCÁRCEL, J., SINGH, R., ZAMORE, P.D. and GREEN, M.R. (1993). The protein Sex-lethal antagonizes the splicing factor U2AF to regulate alternative splicing of transformer pre-mRNA. Nature 362: 171-175.

WATERBURY, J.A., JACKSON, L.L. and SCHEDL, P. (1999). Analysis of the
Doublesex female protein in Drosophila melanogaster. Role in sexual differentiation and behavior and dependence on Intersex. Genetics 152: 1653-1667.

WHITE, M.D.J. (1973). Animal cytology and evolution, $3^{\text {rd }}$ edn. Cambridge University Press, Cambridge, UK.

WILKINS, A.S. (1995). Moving up the hierarchy: a hypothesis on the evolution of a genetic sex determination pathway. BioEssays 17: 71-77.

YAMAMOTO, D., FUJITANI, K., USUI, K., ITO, H. and NAKANO, Y. (1998). From behavior to development: genes for sexual behavior define the neuronal sexual switch in Drosophila. Mech. Dev. 73: 135-146.

\section{Related, previously published Int. J. Dev. Biol. articles}

See our recent Special Issue Fertilization, in honor of David L. Garbers and edited by Paul M. Wassarman and Victor D. Vacquier at: http://www.ijdb.ehu.es/web/contents.php?vol=52\&issue=5-6

See our recent Special Issue Ear Development edited by Fernando Giraldez and Bernd Fritzsch at: http://www.ijdb.ehu.es/web/contents.php?vol=51\&issue=6-7

Characterization of novel genes expressed specifically in the sexual organs of the planarian Dugesia ryukyuensis Sumitaka Hase, Emiko Kashiwagi, Kazuya Kobayashi, Motonori Hoshi and Midori Matsumoto Int. J. Dev. Biol. (2007) 51: 345-349

Gametophyte interaction and sexual reproduction: how plants make a zygote Leonor C. Boavida, Ana Maria Vieira, Jörg D. Becker and José A. Feijó Int. J. Dev. Biol. (2005) 49: 615-632

P450 aromatase expression in the temperature-sensitive sexual differentiation of salamander (Hynobius retardatus) gonads

Natsuko Sakata, Yoichiro Tamori And Masami Wakahara

Int. J. Dev. Biol. (2005) 49: 417-425

Abnormal sex-duct development in female moles: the role of anti-Müllerian hormone and testosterone. Federico Zurita, Francisco J Barrionuevo, Philippe Berta, Esperanza Ortega, Miguel Burgos and Rafael Jiménez Int. J. Dev. Biol. (2003) 47: 451-458

\section{Sex reversal of genetic females $(\mathrm{XX})$ induced by the transplantation of $\mathrm{XY}$ somatic cells in the medaka, Oryzias} latipes.

Al Shinomiya, Naoki Shibata, Mitsuru Sakaizumi and Satoshi Hamaguchi

Int. J. Dev. Biol. (2002) 46: 711-717

mgm 1, the earliest sex-specific germline marker in Drosophila, reflects expression of the gene esg in male stem cells.

Adrian Streit, Luca Bernasconi, Pavel Sergeev, Alex Cruz and Monica Steinmann-Zwicky

Int. J. Dev. Biol. (2002) 46: 159-166

Musca domestica, a window on the evolution of sex-determining mechanisms in insects.

Andreas Dübendorfer, Monika Hediger, Géza Burghardt and Daniel Bopp Int. J. Dev. Biol. (2002) 46: 75-79

Sexual differentiation of the somatic gonad tissue in marine bivalve mollusks: esterase- and fibronectin-like recognition signals

M Paz, A Mikhailov, M Torrado

Int. J. Dev. Biol. (2001) 45: S119-S120

Germ cells, gonads and sex reversal in marsupials.

M B Renfree and G Shaw

Int. J. Dev. Biol. (2001) 45: 557-567
2006 ISI ${ }^{* *}$ Impact Factor $=3.577^{* *}$

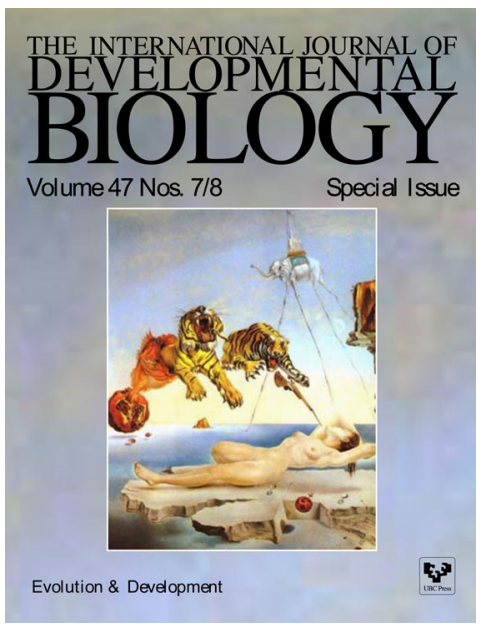

